\title{
Mechanical Properties and Statistical Damage Constitutive Model of Rock under a Coupled Chemical-Mechanical Condition
}

\author{
Yun Lin $\mathbb{D}^{1},{ }^{1,2,3}$ Feng Gao $\mathbb{D}^{1,2}$ Keping Zhou, ${ }^{2}$ Rugao Gao $\mathbb{D}^{2},{ }^{2}$ and Hongquan Guo ${ }^{2}$ \\ ${ }^{1}$ The State Key Laboratory of Safety and Health for Metal Mines of China, Maanshan, Anhui 243000, China \\ ${ }^{2}$ School of Resource and Safety Engineering, Central South University, Changsha, Hunan 410083, China \\ ${ }^{3}$ School of Civil, Environmental and Mining Engineering, University of Adelaide, Adelaide, SA 5005, Australia \\ Correspondence should be addressed to Feng Gao; csugaofeng@csu.edu.cn and Rugao Gao; gaorgcsu@163.com
}

Received 25 November 2018; Revised 18 January 2019; Accepted 16 April 2019; Published 14 May 2019

Academic Editor: Emanuele Tondi

Copyright (c) 2019 Yun Lin et al. This is an open access article distributed under the Creative Commons Attribution License, which permits unrestricted use, distribution, and reproduction in any medium, provided the original work is properly cited.

Chemical corrosion has a significant impact on the damage evolution behavior of rock. To investigate the mechanical damage evolution process of rock under a coupled chemical-mechanical (CM) condition, an improved statistical damage constitutive model was established using the Drucker-Prager (D-P) strength criterion and two-parameter Weibull distribution. The damage variable correction coefficient and chemical damage variable which was determined by porosity were also considered in the model. Moreover, a series of conventional triaxial compressive tests were carried out to investigate the mechanical properties of sandstone specimens under the effect of chemical corrosion. The relationship between rock mechanics properties and confining pressure was also explored to determine Weibull distribution parameters, including the shape parameter $m$ and scale parameter $F_{0}$. Then, the reliability of the damage constitutive model was verified based on experimental data. The results of this study are as follows: (i) the porosity of sandstone increased and the mechanical properties degraded after chemical corrosion; (ii) the relationships among the compressive strength, the peak axial strain, and confining pressures were linear, while the relationships among the elastic modulus, the residual strength, and confining pressures were exponential functions; and (iii) the improved statistical damage constitutive model was in good agreement with the testing curves with $R^{2}>0.98$. It is hoped that the study can provide an alternative method to analyze the damage constitutive behavior of rock under a coupled chemical-mechanical condition.

\section{Introduction}

The interaction between groundwater and rock has a significant influence on the deformation and strength of rock [1]. As known, underground water may lead to many hazards, for example, karst collapse of pillars [2]. In general, underground water is a complex aqueous solution with various ion components and $\mathrm{pH}$ values [3], and the stability of rock mass engineering, such as oil extraction, nuclear waste geological repository, energy underground reservoir, and carbon dioxide geological storage reservoir, is significantly affected by the corrosion of hydrochemical solutions [4-7]. Moreover, the influence of stress conditions on the mechanical behavior of rock is not negligible. Thus, it is of high importance to explore the mechanical behavior of rock under the coupled effects of hydrochemical environment and loading.
Due to the corrosion of chemical solutions, the pore structure would be changed and the physical and mechanical properties of rocks would deteriorate gradually with the increase in chemical damage. Many scholars have explored the effects of chemical corrosion on rock deformation and strength characteristics through theoretical and experimental methods [4, 8-18]. Ning et al. [16] studied the deterioration characteristics of mechanical properties of sandstone under acid corrosion and defined the chemical damage variable based on the change in the effective bearing area of sandstone specimens and then established the degradation equation of the strength and elasticity model. Feng et al. $[9,10]$ experimentally analyzed the evolution law of mechanical properties of rocks under the effect of chemical corrosion combined with neural network simulation and numerical analysis. Ding and Feng [19] studied the evolution laws of mechanical 
properties of limestone under the corrosion effect of different chemical solutions. Feucht and Logan [20], Dieterich and Conrad [21], and Logan and Blackwell [22] experimentally analyzed the deformation of rock immersed in chemical solutions and then explored the relations among compressive strength, elastic modulus, and chemical corrosion. Han et al. $[12,13]$ explored the effects of chemical solutions on the deterioration characteristics of fracture toughness and compressive strength of sandstone under different freezethaw cycle conditions. $\mathrm{Ni}$ et al. [23] investigated the relationship between deterioration of mechanical properties of rock and damage variable of granite under different chemical solutions and freeze-thaw cycles based on experimental data. These researches mainly focus on the influence of chemical corrosion on the mechanical effect and the chemical damage variables of rock, and the results are of great significance.

A reasonable constitutive model is a useful method to investigate the damage evolution behavior of materials [24-26]. In recent years, many damage constitutive models have been established based on various strength theories or criterions, such as rock strain strength theory [27-29], Drucker-Prager (D-P) criterion [30-33], Mohr-Coulomb (M-C) criterion [34-37], and Hoek-Brown (H-B) criterion $[38,39]$. However, the strength of microelements, which is affected by many factors, cannot be calculated accurately using the strain strength theory [39]. Meanwhile, the M-C criterion may cause great error at a high stress level, and the form of $\mathrm{H}-\mathrm{B}$ criterion is too complex because it was developed from experimental results [40]. Though the D-P criterion is conservative in calculating the intensity of the microelement, it is still widely used due to its simple form. In the present work, the D-P criterion is used to describe the strength of microelements. So far, studies on the damage constitutive model of rocks treated with chemical corrosion are limited [41, 42]. Moreover, these studies mainly focused on the constitutive equations of rock under the chemical corrosion and uniaxial compression coupling. As known, the mechanical behaviors of rock under triaxial compression are different, but the chemical-mechanical (CM) coupling damage constitutive model of rock has not been well studied, especially the mechanical behavior in the post-peak stage of rock treated with chemical corrosion. So the results of published literatures are far from fully understanding the characteristics of deformation and destruction of rock affected by coupling chemical corrosion and load. All of these address a need to establish a chemical-mechanical coupling damage constitutive model to explore the mechanical response of rock.

As known, the model parameters in the constitutive models are highly affected by some mechanical properties, such as peak strength, peak axial strain, and elastic modulus $[36,37,39]$. In general, the values of these mechanical properties are obtained by conventional mechanical tests. Obviously, it is inconvenient to calculate the model parameters based on the data of conventional mechanical tests. The reason lies in the fact that the values of mechanical properties will change in response to various confining pressure values $[36,43,44]$. This also addresses a need to develop a more efficient method to obtain mechanics parameters of rocks.
Recently, some methods for quantitative estimation of rock mechanical parameters have been explored. For example, Li et al. [36] established the relationship between peak stress, peak strain, and confining pressure by $\mathrm{M}-\mathrm{C}$ criterion and data fitting. Then they calculated the values of peak stress and peak strain of rock under different confining pressures and verified the applicability of these relationships by the constitutive model established. Yu et al. [45] explored the relationship between peak stress, peak strain, and elastic modulus and confining pressure of rock at different temperatures by data fitting. However, the mechanical behavior of rock after chemical corrosion is different, and further efforts are still needed to determine the model parameters for rock treated with chemical corrosion.

In this work, considering the chemical damage variable and damage variable correction coefficient, an improved statistical damage constitutive model of sandstone after chemical corrosion was established based on two-parameter Weibull distribution and D-P strength criterion. To verify the reliability of the constitutive model, a series of conventional triaxial compression tests of sandstone treated with chemical corrosion were carried out, and the relationships between mechanical properties of sandstone and confining pressures were explored. The Weibull parameters of the improved constitutive model, including the shape parameter $m$ and scale parameter $F_{0}$, were calculated based on these relationships, and then the theoretical curves were simulated and compared with the testing curves. The results showed that the improved model can well reflect the damage evolution behavior of sandstone treated with chemical corrosion.

\section{Statistical Damage Constitutive Model}

2.1. Damage Constitutive Model of Sandstone without Chemical Corrosion. In terms of damaged materials, it is usually difficult to analyze the pattern and damage mechanism of each microelement defect to determine the effective bearing area of the material. In order to measure the damage of materials through intermediate variables, Lemaitre [46] proposed an equivalent strain hypothesis. The hypothesis can be described as the following [47]: the strain generated by the effective stress on the intact materials is equivalent to the strain generated by the nominal stress on the damaged materials. The strain equivalence has been widely used in the establishment of the constitutive model of rock-like materials. Based on the assumption, the effective stress of rock can be represented by the nominal stress, that is,

$$
\sigma_{i}^{*}=\frac{\sigma_{i}}{1-D_{\mathrm{m}}},
$$

where $\sigma_{i}$ is the nominal stress, $\sigma_{i}^{*}$ is the effective stress, and $D_{\mathrm{m}}$ is the material damage variable under load, which measures the degree of material damage. When $D_{\mathrm{m}}=0$, the material is in a nondestructive state. When $D_{\mathrm{m}}=1$, the material completely destroys, and $0<D_{\mathrm{m}}<1$ corresponds to different degrees of damage.

Qian and Yin [48] believed that the residual strength of rock has high influence on the stability of geotechnical 
systems. Based on experimental analysis, $\mathrm{Xu}$ et al. [39] found that the residual strength would become the main factor affecting the softening mechanical behavior in the post-peak stage of the stress-strain curves after macrocracks appear, and the damage variables should be improved in the post-peak stage. Gao et al. [32] improved the damage variable of rock by introducing a damage variable correction coefficient $\lambda$ which was defined as the ratio of the residual strength and the peak strength and verified the reliability of the method using experimental results. In this study, the damage variable correction coefficient $\lambda$ is also applied, $\lambda \in(0,1)$. Then, equation (1) can be written as

$$
\sigma_{i}^{*}=\frac{\sigma_{i}}{1-\lambda D_{\mathrm{m}}}
$$

Then, the strain can be written as equation (3) according to Hooke's law [49].

$$
\varepsilon_{1}=\frac{\sigma_{1}^{*}-\mu\left(\sigma_{2}^{*}+\sigma_{3}^{*}\right)}{E}=\frac{\sigma_{1}-\mu\left(\sigma_{2}+\sigma_{3}\right)}{E\left(1-\lambda D_{\mathrm{m}}\right)}
$$

where $\sigma_{1}, \sigma_{2}$, and $\sigma_{3}$ are three principal stresses; $\varepsilon_{1}$ is the strain which corresponds to the stress of $\sigma_{1} ; E$ is the elastic modulus; and $\mu$ is Poisson's ratio.

Combing equations (2) and (3), the improved statistical damage constitutive model can be expressed as

$$
\sigma_{1}=\left(1-\lambda D_{\mathrm{m}}\right) E \varepsilon_{1}+\mu\left(\sigma_{2}+\sigma_{3}\right)
$$

Under triaxial compression, the rock can be divided into a number of microelements with different defects and the damage of rock microelement is random. Then, we define $N_{t}$ as the number of failed microelements and $N$ is the total number of microelements. The ratio of $N_{t}$ to $N$ could be seen as the mechanical damage variable.

$$
D_{\mathrm{m}}=\frac{N_{t}}{N}
$$

The fracture of rock is caused by the failure of the weakest link according to the theory of fracture mechanics [50]. The Weibull distribution [51] was also proposed based on the weakest link theory and has applied to many groups of problems, for example, the size effect on failure in solids. Assuming that the strength level of the microelements of materials satisfies the Weibull distribution function, Krajcinovic and Silva [52] first proposed to calculate the damage variable of materials based on the Weibull distribution. Then, many scholars applied the distribution to establish various statistical constitutive models of rocks [27, 36, 42, 53-55].

On the other hand, the expression of the Weibull distribution can be divided into two kinds, i.e., three-parameter
Weibull distribution and two-parameter Weibull distribution. The expression of the three-parameter Weibull distribution is $[32,55]$

$$
P(F)=\frac{m}{F_{0}}\left(\frac{F-\gamma}{F_{0}}\right)^{m-1} e^{-\left(F-\gamma / F_{0}\right)^{m}}
$$

where $P(F)$ is the microelement strength distribution function, $F$ is the parameter which indicates the strength level of the microelement, $m$ is the shape parameter denoting the degree of homogeneity, $F_{0}$ is the scale parameter associated with the strength of microelements, and $\gamma$ is the position parameter which represents the damage evolution threshold.

In most cases, the threshold $\gamma$ is assumed to be zero [56]. Then, it becomes the two-parameter Weibull distribution and could be expressed as

$$
P(F)=\frac{m}{F_{0}}\left(\frac{F}{F_{0}}\right)^{m-1} e^{-\left(F / F_{0}\right)^{m}}
$$

Quinn (Quinn and Quinn 2010) believed that it is very risky to assume that a finite threshold strength exists without careful screening or nondestructive evaluation, and the twoparameter Weibull function is the most commonly used for simplicity. Deng et al. [56] found that the two-parameter Weibull function is sufficient suitable for describing the statistical strength variation of materials. Moreover, the two-parameter Weibull distribution is the most widely accepted function in the treatment of rock properties, and the results of a large number of studies indicate that it is capable of describing the statistical strength of rock microelements [30, 36, 53, 54, 57, 58]. Therefore, it is appropriate to introduce the two-parameter Weibull distribution to calculate the damage variable of rocks.

Then, the damage variable $D_{\mathrm{m}}$ can be obtained based in equations (5) and (7).

$$
D_{\mathrm{m}}=\int_{0}^{F} P(F) \mathrm{d} F=\int_{0}^{F} \frac{m}{F_{0}}\left(\frac{F}{F_{0}}\right)^{m-1} e^{-\left(F / F_{0}\right)^{m}} \mathrm{~d} x=1-e^{-\left(F / F_{0}\right)^{m}}
$$

Combining equation (8) and equation (4), the improved statistical damage constitutive model is

$$
\sigma_{1}=E \varepsilon_{1}\left[1-\lambda+\lambda e^{-\left(F / F_{0}\right)^{m}}\right]+\mu\left(\sigma_{2}+\sigma_{3}\right)
$$

2.2. Damage Constitutive Model of Sandstone under a Coupled CM Condition. Under the action of chemical corrosion and loading, the rocks show different damage characteristics. The chemical-mechanical coupling damage can be 
obtained by the generalized damage variables derived from the equivalent strain principle, and the total damage variable can be expressed as [39]

$$
D=D_{\mathrm{c}}+D_{\mathrm{m}}-D_{\mathrm{c}} D_{\mathrm{m}}
$$

where $D$ is the total damage variable and $D_{c}$ is the chemical damage variable.

Thus, the damage variable in equation (4) should be replaced by the total damage variable in equation (10). Then the damage constitutive model of sandstones after chemical corrosion is as follows:

$$
\sigma_{1}=E \varepsilon_{1}\left(1-D_{\mathrm{c}}\right)\left(1-D_{\mathrm{m}}\right)+2 \mu \sigma_{3}
$$

Combining equations (8) and (11), the improved damage constitutive model of rock treated with chemical corrosion can be expressed as

$$
\sigma_{1}=\left(1-D_{c}\right) E \varepsilon_{1}\left[1-\lambda+\lambda e^{-\left(F / F_{0}\right)^{m}}\right]+\mu\left(\sigma_{2}+\sigma_{3}\right) .
$$

2.3. Chemical Damage Variable. According to equation (12), the chemical damage variable has a significant influence on the mechanical evolution behavior of rock. Thus, the determination of the chemical damage variable should be identified firstly to establish the damage constitutive model of rock. Mechanical properties have been widely used to calculate the damage variable $[28,59]$, such as maximum strain, elastic modulus, and residual strain. However, it is not easy to obtain the value of mechanical property which depends on a large number of mechanical tests. Therefore, other simple, fast, and convenient methods have been explored by many scholars, such as the chemical damage variable based on CT number [60-62] and rock density [63-65]. Note that CT number, which can be expressed by the change rate of the attenuation coefficient of water, is often used to describe the attenuation coefficient of rock materials relative to the attenuation coefficient of water [60]. The change in porosity has also been widely used to define the damage variable of rock $[12,16,23,66]$. Due to that, the porosity can be obtained by nuclear magnetic resonance (NMR) technique easily; the chemical damage variable characterized in terms of porosity is also used in this study, and it can be expressed as [67]

$$
D_{\mathrm{c}}=\frac{\varnothing_{t}-\varnothing_{0}}{1-\varnothing_{0}}
$$

where $\varnothing_{t}$ is the porosity of sandstone treated with chemical corrosion, and $\varnothing_{0}$ is the initial porosity.

Let $E_{0}$ be the elastic modulus of rock without chemical corrosion, then the elastic modulus and improved damage constitutive model of rock treated with chemical corrosion can be expressed as

$$
\left\{\begin{array}{l}
E=\left(\frac{1-\varnothing_{t}}{1-\varnothing_{0}}\right) E_{0}, \\
\sigma_{1}=E \varepsilon_{1}\left[1-\lambda+\lambda e^{-\left(F / F_{0}\right)^{m}}\right]+\mu\left(\sigma_{2}+\sigma_{3}\right) .
\end{array}\right.
$$

2.4. Determination of $m$ and $F_{0}$. A reasonable measurement of the strength level of microelements in rock is the key to establishing the damage evolution equation based on the theory of statistical damage. Li and Tang $[29,68,69]$ preliminarily established a statistical damage evolution model of rocks using axial strain to measure the strength level of microelements. As known, the strength level of the rock microelement is not directly determined by the axial strain, but directly related to the stress state of the rock microelement. Therefore, it is unreasonable to adopt the axial strain to measure the strength level of the rock microelement. Some strength criterions have also been used to measure the strength of the microelement, where the Drucker-Prager yield criterion $[70]$ is the most commonly used $[30,33,71,72]$. In this study, the $\mathrm{D}-\mathrm{P}$ criterion is proposed to measure the strength level of the rock microelement.

The D-P criterion is a generalized Mises yield criterion, which takes into account the effect of intermediate principal stress and hydrostatic pressure. It has a simple form and is widely used in geotechnical engineering. The expression is [73]

$$
F=\partial_{0} I_{1}+\sqrt{J_{2}}=k_{0}
$$

where $\partial_{0}$ and $k_{0}$ are material parameters, $I_{1}$ and $J_{2}$ are the first invariant of the stress tensor and the second invariant of the stress deviator, respectively, and the parameters can be expressed as

$$
\left\{\begin{array}{c}
\partial_{0}=\frac{\sin \varphi}{\sqrt{9+3 \sin ^{2} \varphi}}, \\
I_{1}=\sigma_{1}^{*}+\sigma_{2}^{*}+\sigma_{3}^{*}, \\
J_{2}=\frac{\left(\sigma_{1}^{*}-\sigma_{2}^{*}\right)^{2}+\left(\sigma_{2}^{*}-\sigma_{3}^{*}\right)^{2}+\left(\sigma_{3}^{*}-\sigma_{1}^{*}\right)^{2}}{6},
\end{array}\right.
$$

where $\sigma_{1}^{*}, \sigma_{2}^{*}$, and $\sigma_{3}^{*}$ are effective stresses and $\varphi$ is the internal friction angle.

Combining equations (2), (4), (15), and (16), the strength level of microelement $F$ can be calculated easily as

$$
F=\frac{\partial_{0} I_{1}^{\prime}+\sqrt{J_{2}^{\prime}}}{\sigma_{1}-\mu\left(\sigma_{2}+\sigma_{3}\right)} E \varepsilon_{1},
$$

where $I_{1}^{\prime}=\sigma_{1}+\sigma_{2}+\sigma_{3}$ and $J_{2}^{\prime}=1 / 6\left[\left(\sigma_{1}-\sigma_{2}\right)^{2}+\left(\sigma_{2}-\sigma_{3}\right)^{2}\right.$ $\left.+\left(\sigma_{1}-\sigma_{3}\right)^{2}\right]$. 
Under the condition of conventional triaxial compression testing, $\sigma_{1}>\sigma_{2}=\sigma_{3}$, then the strength of microelement $F$ can be calculated as

$$
F=\frac{\partial_{0} I_{1}^{\prime}+\sqrt{J_{2}^{\prime}}}{\sigma_{1}-2 \mu \sigma_{3}} E \varepsilon_{1} .
$$

Substituting equation (15) into equation (9), and then differentiating equation (9), the following expression can be obtained:

$$
\begin{aligned}
\frac{d \sigma_{1}}{d \varepsilon_{1}}= & E\left[1-\lambda+\lambda e^{-\left(F / F_{0}\right)^{m}}\right]-\lambda m E \varepsilon_{1} \frac{F^{m-1}}{F_{0}{ }^{m}} e^{-\left(F / F_{0}\right)^{m}} \\
& \cdot\left\{\partial_{0}\left[\frac{E\left(\sigma_{1}+2 \sigma_{3}\right)}{\sigma_{1}-2 \mu \sigma_{3}}+\frac{E \varepsilon_{1}}{\sigma_{1}-2 \mu \sigma_{3}} \frac{d \sigma_{1}}{d \varepsilon_{1}}-\frac{E \varepsilon_{1}\left(\sigma_{1}+2 \sigma_{3}\right)}{\left(\sigma_{1}-2 \mu \sigma_{3}\right)^{2}} \frac{d \sigma_{1}}{d \varepsilon_{1}}\right]\right. \\
& \left.+\frac{E\left(\sigma_{1}-\sigma_{3}\right)+E \varepsilon_{1}\left(d \sigma_{1} / d \varepsilon_{1}\right)}{\sqrt{3}\left(\sigma_{1}-2 \mu \sigma_{3}\right)}-\frac{E \varepsilon_{1}\left(\sigma_{1}-\sigma_{3}\right)}{\sqrt{3}\left(\sigma_{1}-2 \mu \sigma_{3}\right)^{2}} \frac{d \sigma_{1}}{d \varepsilon_{1}}\right\} .
\end{aligned}
$$

According to the characteristics of the curve of stressstrain of rocks, equation (9) satisfies the following geometrical conditions of the peak point $P$ on the curve:

$$
\left\{\begin{array}{l}
\frac{d \sigma_{1}}{d \varepsilon_{1}}=0 \\
\varepsilon_{1}=\varepsilon_{\mathrm{p}} \\
\sigma_{1}=\sigma_{\mathrm{p}}
\end{array}\right.
$$

where $\sigma_{\mathrm{p}}$ is the peak stress of rock and $\varepsilon_{\mathrm{p}}$ is the strain corresponding to the peak stress, which is called the peak strain in this study.

Then, we have

$$
\left\{\begin{array}{l}
\sigma_{\mathrm{p}}=E \varepsilon_{\mathrm{p}}\left[1-\lambda+\lambda e^{-\left(F_{\mathrm{p}} / F_{0}\right)^{m}}\right]+2 \mu \sigma_{3}, \\
\frac{m F_{\mathrm{p}}^{m-1}}{F_{0}^{m}}=\frac{\left(\sigma_{\mathrm{p}}-2 \mu \sigma_{3}\right)^{2}}{E \varepsilon_{\mathrm{p}}\left[\sigma_{\mathrm{p}}-2 \mu \sigma_{3}+(\lambda-1) E \varepsilon_{\mathrm{p}}\right]\left[\partial_{0}\left(\sigma_{\mathrm{p}}+2 \sigma_{3}\right)+1 / \sqrt{3}\left(\sigma_{\mathrm{p}}-\sigma_{3}\right)\right]},
\end{array}\right.
$$

where $F_{\mathrm{p}}$ is the strength of the microelement when the axial stress reaches the peak value.

Solving equation (21), the parameter $m$ and $F_{0}$ can be calculated as

$$
\left\{\begin{array}{c}
m=\frac{\sigma_{\mathrm{p}}-2 \mu \sigma_{3}}{\left[\sigma_{\mathrm{p}}-2 \mu \sigma_{3}+(\lambda-1) E \varepsilon_{\mathrm{p}}\right] \ln \left(\lambda E \varepsilon_{\mathrm{p}} / \sigma_{\mathrm{p}}-2 \mu \sigma_{3}+(\lambda-1) E \varepsilon_{\mathrm{p}}\right)}, \\
F_{0}=\frac{\partial_{0}\left(\sigma_{\mathrm{p}}+2 \sigma_{3}\right)+1 / \sqrt{3}\left(\sigma_{\mathrm{p}}-\sigma_{3}\right)}{\left(\sigma_{\mathrm{p}}-2 \mu \sigma_{3}\right)\left[\ln \left(\lambda E \varepsilon_{\mathrm{p}} / \sigma_{\mathrm{p}}-2 \mu \sigma_{3}+(\lambda-1) E \varepsilon_{\mathrm{p}}\right)\right]^{1 / m}} .
\end{array}\right.
$$

Then the improved constitutive model of rock under chemical-loading conditions was established by combining

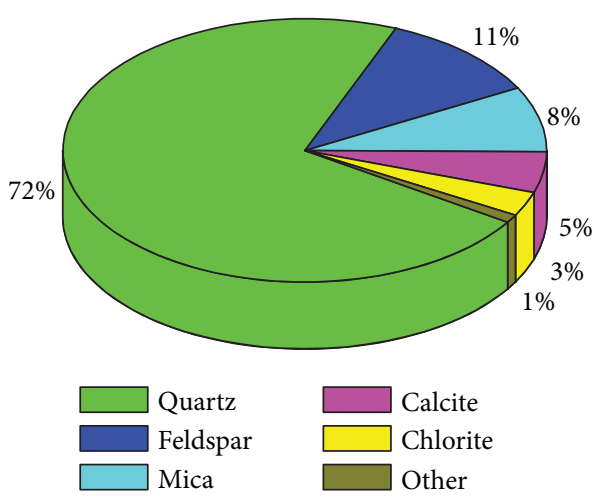

FIgURE 1: The average mineral composition content of sandstone specimen.

equations (14) and (22). To analyze the reliability and feasibility of the improved model, the damage constitutive model without the damage variable correction coefficient can be expressed as equation (23). In the model, the parameters $m$ and $F_{0}$ can also be determined based on the above method, which is not described in this study.

$$
\sigma_{1}=E \varepsilon_{1} e^{-\left(F / F_{0}\right)^{m}}+2 \mu \sigma_{3}
$$

\section{Tests of Porosity and Triaxial Mechanical Properties}

3.1. Materials and Experimental Methods. To analyze the change in porosity and the mechanical properties of rock treated with chemical corrosion and verify the reliability of the improved constitutive model established in this work, a series of conventional triaxial compression tests were conducted. The rock used in this study is fine-grained sandstone collected from Hunan Province, China. The selected rock samples belong to the same block to ensure the reliability of the test results. According to the standards of ISRM suggested $[74,75]$, these sandstones are cylinders with diameter of $50 \pm 1 \mathrm{~mm}$ and height of $100 \pm 1 \mathrm{~mm}$. In addition, the specimens with larger discreteness were excluded by comparing the quality and longitudinal wave velocity (LWV) of specimens. The mean density and LWV of specimens retained are $2.41 \mathrm{~g} / \mathrm{cm}^{3}$ and $2310 \mathrm{~m} / \mathrm{s}$, respectively. The mineral components of the specimens were detected by X-ray detection, and the results are listed in Figure 1. It can be found that the mineral composition of sandstone is mainly quartz, feldspar, mica, calcite, etc.

Since the chemical corrosion of rock mass engineering is a long-term and slow process $[4,11,76]$, chemical solutions with large concentration were selected to observe the effect of chemical solutions on rock in a laboratory environment. In the tests, three chemical solutions were prepared, i.e., an acidic solution with $0.01 \mathrm{~mol} / \mathrm{L} \mathrm{H}_{2} \mathrm{SO}_{4}(\mathrm{pH}=2)$, distilled water $(\mathrm{pH}=7)$, and an alkaline solution with $0.01 \mathrm{~mol} / \mathrm{L}$ $\mathrm{NaOH}(\mathrm{pH}=12)$. Specimens were divided into four sets, i.e., A, B, C, and D. Specimens of groups A, B, and C were immersed in $\mathrm{H}_{2} \mathrm{SO}_{4}$ solution, $\mathrm{NaOH}$ solution, and distilled 
TABLE 1: Parameters of sandstone under the conditions of different chemical corrosions.

\begin{tabular}{|c|c|c|c|c|c|c|c|c|c|c|}
\hline Chemical environment & $\begin{array}{c}\text { Confining pressures } \\
(\mathrm{MPa})\end{array}$ & $\sigma_{\mathrm{p}}(\mathrm{mPa})$ & $\varepsilon_{\mathrm{p}}$ & $E(\mathrm{GPa})$ & $\begin{array}{c}\text { Residual strength } \\
\sigma_{\mathrm{r}}(\mathrm{MPa})\end{array}$ & $\begin{array}{l}\varnothing_{0} \\
(\%)^{*}\end{array}$ & $\begin{array}{l}\varnothing_{t} \\
(\%)\end{array}$ & $c(\mathrm{MPa})$ & $\varphi\left({ }^{\circ}\right)$ & $\mu$ \\
\hline \multirow{6}{*}{$\mathrm{H}_{2} \mathrm{SO}_{4}$ solution } & 0 & 52.45 & 0.0102 & 9.19 & 28.26 & 5.06 & 10.76 & \multirow{6}{*}{14.90} & \multirow{6}{*}{30.55} & \multirow{6}{*}{0.28} \\
\hline & 5 & 66.98 & 0.0108 & 10.52 & 38.63 & 5.12 & 10.63 & & & \\
\hline & 10 & 83.17 & 0.0119 & 11.61 & 58.59 & 5.04 & 10.81 & & & \\
\hline & 15 & 98.18 & 0.0124 & 12.15 & 65.07 & 5.09 & 10.77 & & & \\
\hline & 20 & 113.59 & 0.0135 & 12.75 & 74.25 & 5.10 & 10.85 & & & \\
\hline & 25 & 128.86 & 0.0143 & 12.93 & 82.78 & 5.13 & 10.82 & & & \\
\hline \multirow{6}{*}{$\mathrm{NaOH}$ solution } & 0 & 55.74 & 0.0096 & 9.41 & 30.13 & 5.04 & 8.65 & \multirow{6}{*}{15.78} & \multirow{6}{*}{31.37} & \multirow{6}{*}{0.26} \\
\hline & 5 & 72.97 & 0.0104 & 10.84 & 41.12 & 5.03 & 8.59 & & & \\
\hline & 10 & 87.54 & 0.0117 & 11.93 & 61.49 & 5.12 & 8.66 & & & \\
\hline & 15 & 103.75 & 0.0125 & 12.18 & 70.65 & 5.08 & 8.57 & & & \\
\hline & 20 & 119.68 & 0.0134 & 12.86 & 82.23 & 5.14 & 8.62 & & & \\
\hline & 25 & 135.48 & 0.0143 & 13.27 & 93.81 & 5.06 & 8.64 & & & \\
\hline \multirow{6}{*}{ Distilled water } & 0 & 63.13 & 0.0094 & 10.48 & 33.96 & 5.11 & 5.92 & \multirow{6}{*}{16.68} & \multirow{6}{*}{33.60} & \multirow{6}{*}{0.26} \\
\hline & 5 & 78.95 & 0.0102 & 11.37 & 44.28 & 5.02 & 5.90 & & & \\
\hline & 10 & 96.24 & 0.0122 & 12.24 & 64.29 & 5.09 & 5.87 & & & \\
\hline & 15 & 114.32 & 0.0131 & 12.63 & 73.04 & 5.12 & 5.94 & & & \\
\hline & 20 & 132.52 & 0.0138 & 12.95 & 85.75 & 4.96 & 5.84 & & & \\
\hline & 25 & 149.11 & 0.0149 & 13.65 & 97.29 & 5.06 & 5.89 & & & \\
\hline \multirow{6}{*}{ Natural state } & 0 & 64.63 & 0.0092 & 10.83 & 39.56 & 5.12 & 5.12 & \multirow{6}{*}{17.13} & \multirow{6}{*}{34.07} & \multirow{6}{*}{0.25} \\
\hline & 5 & 81.57 & 0.0101 & 11.41 & 65.31 & 5.06 & 5.06 & & & \\
\hline & 10 & 100.95 & 0.0120 & 12.52 & 81.37 & 5.08 & 5.08 & & & \\
\hline & 15 & 117.75 & 0.0129 & 12.94 & 93.91 & 5.07 & 5.07 & & & \\
\hline & 20 & 135.28 & 0.0139 & 13.21 & 102.36 & 5.11 & 5.11 & & & \\
\hline & 25 & 153.23 & 0.0151 & 13.81 & 107.93 & 5.10 & 5.10 & & & \\
\hline
\end{tabular}

Note: $c$ : cohesion of rocks.

water, and specimens of group D were in the natural state and used as references.

According to previous literatures [59, 77-84], the porosity could be tested by nuclear magnetic resonance (NMR). In this study, the AniMR-150 NMR imaging system of Central South University (China) was used to measure the porosity of sandstone treated with different chemical corrosions. Since the porosity increments of specimens from all groups are very small (almost 0 ) after 50 days of immersion, then the porosity with immersion time of 50 days is selected as the final porosity of sandstone specimens treated with chemical corrosion.

The conventional triaxial compression tests with various confining pressures $(0,5,10,15,20,25$, and $30 \mathrm{MPa})$ were conducted on the MTS 815 material testing system with a maximum loading capability of $2600 \mathrm{kN}$. The experiment used the axial stress control, and the loading rate was a constant of $0.1 \mathrm{kN} / \mathrm{s}$. During testing, the load and displacement were recorded directly by the system. In this study, the triaxial compressive strength was the peak load when the specimen failed, and the elastic modulus was the slope of the approximate line segment in the stress-strain curve. Note that there are three samples in each group, and the results are the average values of each group.
3.2. Experimental Results. Table 1 displays the average results of porosity and mechanical parameters of sandstone sample immersion in different chemical solutions. Note that the results of sandstone under the confining pressure of $30 \mathrm{MPa}$ were used to verify the feasibility of the improved constitutive model, and the experimental data was not discussed in this section.

From Table 1, it can be seen that the porosity increases when sandstone specimens immersed in chemical solutions, and the porosity change of specimens immersed in $\mathrm{H}_{2} \mathrm{SO}_{4}$ solution is the largest, followed by that of specimens immersed in $\mathrm{NaOH}$ solution and distilled water, respectively. Thus, the order of the chemical damage variable of sandstone specimens treated with different chemical corrosion is $D_{\mathrm{H} 2 \mathrm{SO} 4}>D_{\mathrm{NaOH}}>D_{\text {water }}$. In terms of mechanical properties of sandstone in the same chemical environment, the peak strength, peak axial strain, elastic modulus, and residual strength increase with the increase in confining pressures. Under the condition of the same confining pressure, the peak strength, elastic modulus, and residual strength decrease with the chemical damage variable increasing, while the peak axial strain shows no apparent trend. Meanwhile, it can also be found that the internal friction angle and the cohesion decrease with the chemical damage variable increasing, while 


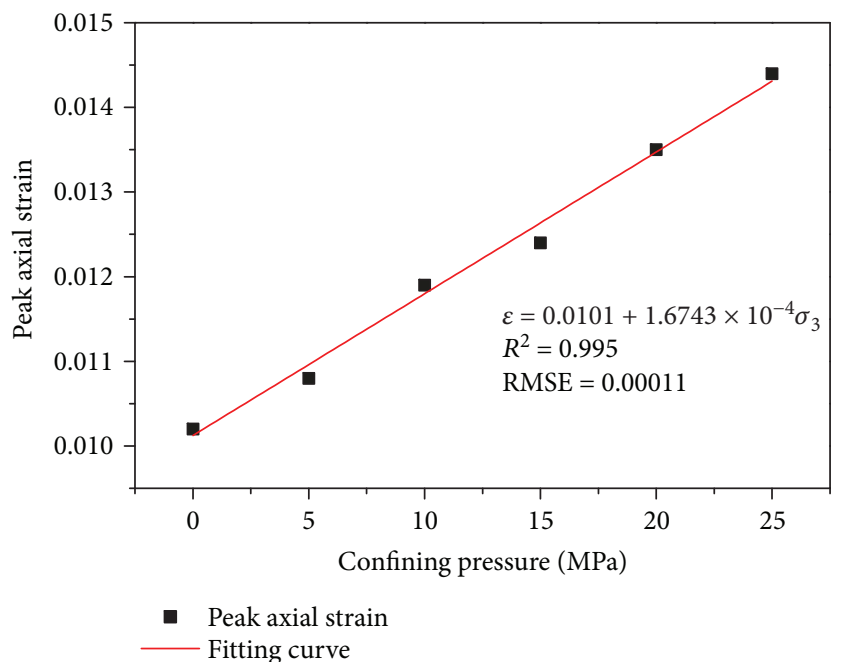

(a)

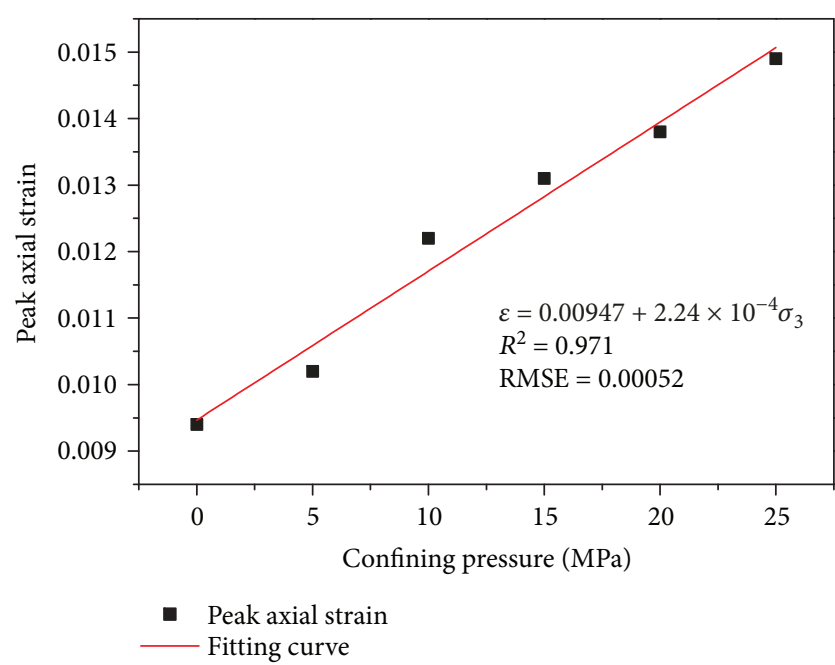

(c)

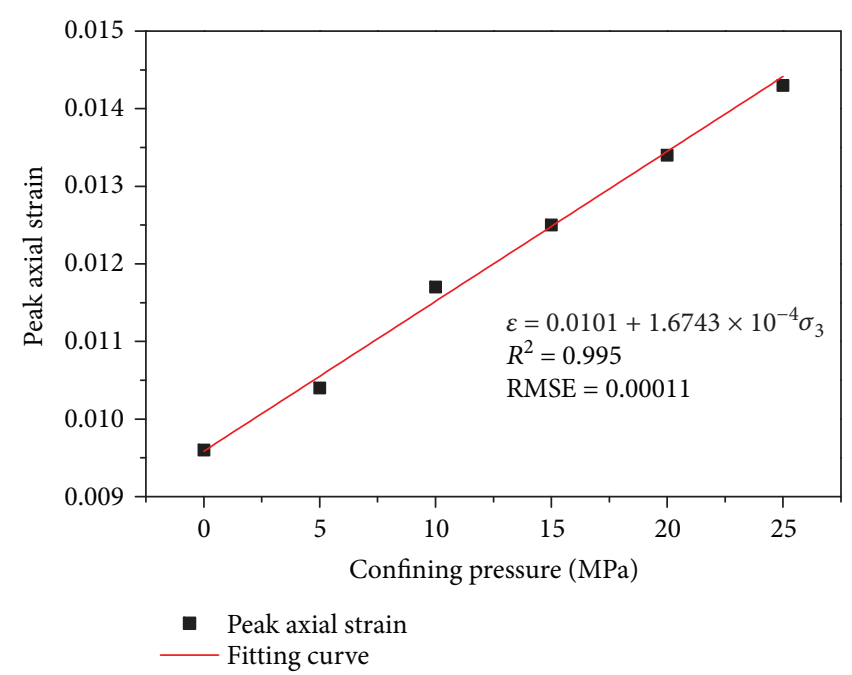

(b)

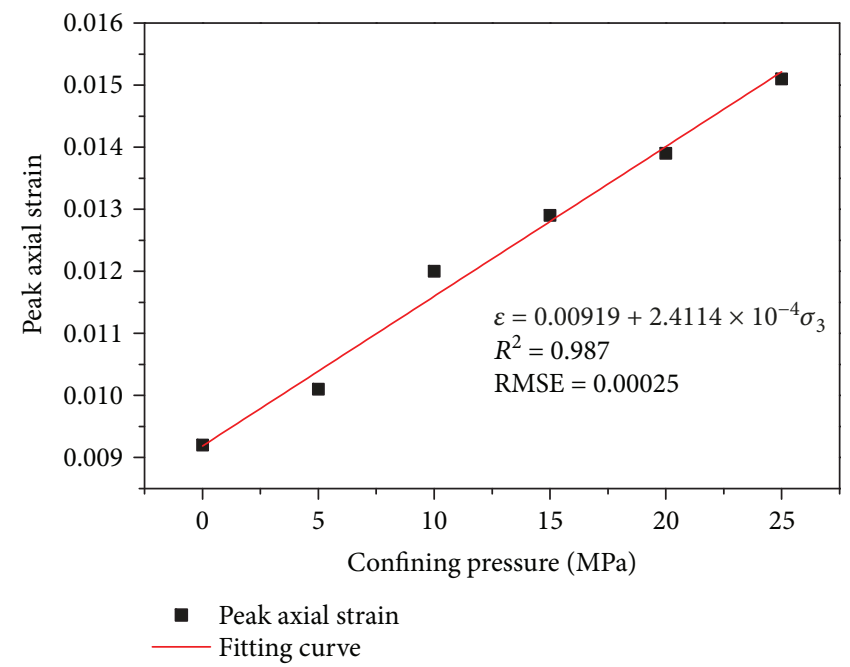

(d)

FIgURE 2: Peak axial strain at various confining pressures of sandstone specimens treated with different chemical corrosions. The chemical environment is (a) $\mathrm{H}_{2} \mathrm{SO}_{4}$ solution, (b) $\mathrm{NaOH}$ solution, (c) distilled water, and (d) natural state.

the evolution law of Poisson's ratio is opposite. Overall, we can draw that the mechanical properties deteriorate under the condition of chemical corrosion, and the ascending order of the effect of chemical solution on mechanical properties is distilled water, $\mathrm{NaOH}$ solution, and $\mathrm{H}_{2} \mathrm{SO}_{4}$ solution, respectively.

3.3. Relationships between Mechanical Properties and Confining Pressures. From equation (22), it is obvious that the mechanical properties, such as $\sigma_{\mathrm{p}}, \varepsilon_{\mathrm{p}}, E$, and $\sigma_{\mathrm{r}}$, contribute to the determination of $m$ and $F_{0}$. However, the values of the four mechanical parameters will change in response to various confining pressures, and they must be remeasured by a series of mechanical tests. This seems to be a rather awkward situation for the operation of the above method. Therefore, further efforts are still needed for the estimation of $\sigma_{\mathrm{p}}, \varepsilon_{\mathrm{p}}, E$, and $\sigma_{\mathrm{r}}$.
According to the previous studies $[36,39,85]$, the four mechanical properties have a certain relationship with confining pressures. Many studies suggested that it is a feasible method to obtain the mechanical parameters of rocks under different confining pressures by experimental fitting with small amounts of data. For example, Alam et al. (Alam et al. 2014) explored the relationship among triaxial strength, tangent modulus, and confining pressure using four points (different confining pressures). Li et al. [36] discussed the relationship among stress, peak axial strain, and confining pressure through six points and then verified the statistical damage constitutive model established in the literature. By fitting five sets of data, the relationship among stress, elastic modulus, and confining pressure was studied by $\mathrm{Xu}$ and Karakus [86]. Wang et al. [47] investigated the relationship among strain, elastic modulus, and confining pressure using six confining pressures. Golshani et al. (Golshani et al. 2006) established the relationship 
TABLE 2: Regression results of peak axial strain versus confining pressures of sandstone treated with different chemical corrosions.

\begin{tabular}{lcccc}
\hline Chemical environment & $a$ & $b$ & Correlative coefficients $R^{2}$ & RMSE \\
\hline $\mathrm{H}_{2} \mathrm{SO}_{4}$ solution & $1.6743 \times 10^{-4}$ & 0.01010 & 0.995 & 0.995 \\
$\mathrm{NaOH}$ solution & $1.9314 \times 10^{-4}$ & 0.00959 & 0.971 & $1.2 \times 10^{-4}$ \\
Distilled water & $2.24 \times 10^{-4}$ & 0.00947 & 0.987 & $5.2 \times 10^{-4}$ \\
Natural state & $2.4114 \times 10^{-4}$ & 0.00919 & $2.5 \times 10^{-4}$ \\
\hline
\end{tabular}

between stress and confining pressure using six points. Based on six sets of data, Yoshinaka et al. (Yoshinaka et al. 2008) established the relationship between Young's modulus and confining pressure. Therefore, the method of experimental fitting is also used to determine the values of the four mechanical properties under different confining pressures in this study.

3.3.1. Peak Strength and Peak Axial Strain. The triaxial strength of rock under a confining pressure could be obtained by a certain strength criterion. The mostly widely used strength criterion is the Mohr-Coulomb strength criterion, and the criterion has been successfully used in many studies [36, 87-90] to obtain the peak axial stress of rocks. The $\mathrm{M}-\mathrm{C}$ criterion is also adopted in this study, and then the peak axial stress of sandstone specimens can be expressed as

$$
\sigma_{\mathrm{p}}=\frac{1+\sin \varphi}{1-\sin \varphi} \sigma_{3}+\frac{2 c \cos \varphi}{1-\sin \varphi}
$$

From equation (24), the value of the peak axial stress of sandstone under different confining pressures could be obtained based on the experimental data in Table 1.

The peak axial strain has a strong linear relationship (shown in equation (25)) with confining pressures $[13,36,86]$. Based on the experimental data in Table 1 , the relationship between the peak axial strain and confining pressures of sandstone specimens treated with different chemical corrosion are regressed in Figure 2.

$$
\varepsilon_{\mathrm{p}}=a \sigma_{3}+b
$$

where $a$ and $b$ are constants. It is obvious that $\varepsilon_{\mathrm{p}}$ is the peak axial strain of rock under uniaxial compression when the confining pressure is zero, then the parameter $b$ is the strain of rock under uniaxial compression, and $a$ represents the strain increasing rate with the increasing of confining pressure.

To evaluate the performance of the fitting curves, the root mean square error (RMSE) and coefficient of determination $\left(R^{2}\right)$ were introduced $[30,91] . R^{2}$ measures how well the association is between changes in two variables, and RMSE is used to find the sample standard deviation of the error

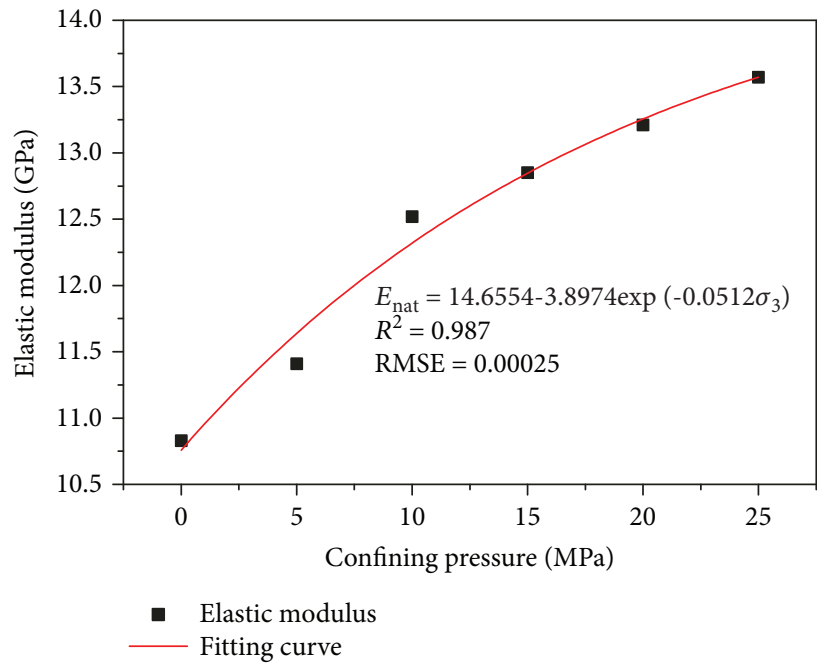

FIGURE 3: Elastic modulus of sandstone specimens under a natural state with various confining pressures.

between regressed and actual values. An ideal regression curve has $R^{2}=1$ and $\mathrm{RMSE}=0$.

$$
\begin{aligned}
R^{2} & =1-\frac{n-1}{n-2} \times \frac{\sum_{i=1}^{n}\left(y_{i}^{\prime}-y_{i}\right)^{2}}{\sum_{i=1}^{n}\left(y_{i}^{\prime}-y_{\mathrm{a}}\right)^{2}}, \\
\mathrm{RMSE} & =\sqrt{\frac{1}{n} \times \sum_{i=1}^{n}\left(y_{i}^{\prime}-y_{i}\right)^{2}},
\end{aligned}
$$

where $n$ is the number of data points, and $y_{i}, y_{i}^{\prime}$, and $y_{\mathrm{a}}$ are the fitting value, the actual value, and the average value of the stress at the $i$ th data point.

The relationships between the peak axial strain and confining pressure are expressed in Table 2. It can be found that the linear relationship fits well the experimental data with $R^{2}>0.97$ and $\mathrm{RMSE}<6.0 \times 10^{-4}$. Then, the peak axial strain of sandstone specimens under different confining pressures can be calculated based on the fitting results.

3.3.2. Elastic Modulus. Figure 3 gives the elastic modulus of sandstone specimens with different confining pressures in the natural state. We can see that the increasing rate of elastic modulus decreases gradually with the confining pressure increasing, indicating that the relationship between elastic modulus and confining pressures could be fitted by an exponential equation shown in equation (27), which has been 
TABLE 3: Elastic modulus of sandstone specimens treated with chemical corrosion at various confining pressures.

\begin{tabular}{|c|c|c|c|c|}
\hline Chemical environment & Confining pressures $(\mathrm{MPa})$ & Actual elastic modulus (GPa) & Predicted elastic modulus (GPa) & Error (\%) \\
\hline \multirow{6}{*}{$\mathrm{H}_{2} \mathrm{SO}_{4}$ solution } & 0 & 9.19 & 10.11 & 10.03 \\
\hline & 5 & 10.52 & 10.96 & 4.21 \\
\hline & 10 & 11.61 & 11.57 & 0.34 \\
\hline & 15 & 12.15 & 12.08 & 0.59 \\
\hline & 20 & 12.75 & 12.45 & 2.33 \\
\hline & 25 & 12.93 & 12.76 & 1.33 \\
\hline \multirow{6}{*}{$\mathrm{NaOH}$ solution } & 0 & 9.41 & 10.35 & 9.98 \\
\hline & 5 & 10.84 & 11.20 & 3.34 \\
\hline & 10 & 11.93 & 11.86 & 0.59 \\
\hline & 15 & 12.18 & 12.37 & 1.60 \\
\hline & 20 & 12.86 & 12.77 & 0.71 \\
\hline & 25 & 13.27 & 13.06 & 1.58 \\
\hline \multirow{6}{*}{ Distilled water } & 0 & 10.48 & 10.67 & 1.78 \\
\hline & 5 & 11.37 & 11.53 & 1.41 \\
\hline & 10 & 12.24 & 12.22 & 0.18 \\
\hline & 15 & 12.63 & 12.74 & 0.84 \\
\hline & 20 & 12.95 & 13.13 & 1.41 \\
\hline & 25 & 13.65 & 13.45 & 1.44 \\
\hline
\end{tabular}

proposed and verified by Pourhosseini and Shabanimashcool [40] and Yang et al. [85].

$$
E=a^{\prime}+b^{\prime} \exp \left(d \sigma_{3}\right)
$$

where $a^{\prime}, b^{\prime}$, and $d$ are constants which can be obtained by exponential fitting.

When the confining pressure is zero, then $E=a^{\prime}+b^{\prime}$ is the elastic modulus of rock under the uniaxial compressive state. So the parameter $d$ is a fitting coefficient defining the increasing rate of elastic modulus with the increasing of confining pressures.

Using the method, the regression result of sandstone specimens under the natural state is shown in Figure 3 and the fitting equation is listed in equation (28). It can be seen that the exponential equation can fit the experimental data well with $R^{2}=0.971$ and $\mathrm{RMSE}=0.1411$.

$$
E_{\text {nat }}=14.6554-3.8974 \exp \left(-0.0512 \sigma_{3}\right)\left(R^{2}=0.971\right) \text {, }
$$

where $E_{\text {nat }}$ represents the elastic modulus of sandstone specimens under natural state.

As mentioned in Sections 2.2 and 2.3, the elastic modulus of sandstone specimens under the effect of loading and chemical corrosion could be described as

$$
E=\left(1-D_{\mathrm{c}}\right) E_{\text {nat }}=\frac{1-\varnothing_{t}}{1-\varnothing_{0}} E_{\text {nat }} .
$$

Combining equation (29) and the porosity of sandstone specimens under different states in Table 1 , the elastic modulus of sandstone specimens immersed in different chemical solutions are calculated and listed in Table 3. It is obvious that the error between the actual and predicted elastic modulus is less than $11 \%$. Thus, it is feasible to calculate the elastic modulus of sandstone specimens under a coupled chemical-mechanical condition by using equations (28) and (29).

3.3.3. Residual Strength. Under the condition of different chemical corrosions, the testing results of the average residual strength with various confining pressures and the fitting curves are shown in Figure 4. The regression results listed in Table 4 reveal that the relationship between residual strength and confining pressures can be expressed by exponential equations $\left(R^{2}>0.97\right.$, RMSE $\left.<2.5\right)$, which is similar to the results of $\mathrm{Xu}$ et al. [39].

\section{Verification of the Improved Damage Constitutive Model}

In this study, the experiment results of conventional triaxial compression tests of sandstone treated with different chemical corrosions under a confining pressure of $30 \mathrm{MPa}$ were used to verify the reliability of the improved damage constitutive model. The mechanical parameters of sandstone under the confining pressure of $30 \mathrm{MPa}$, which are used to simulate the mechanical behavior based on the improved damage constitutive model, can be calculated according to the relationships between mechanical properties and confining pressures in Section 3.3. The damage variable correction coefficient $\lambda$ can be calculated based on the definition in Section 2.1. Then, the model parameters are obtained and listed in Table 5. 


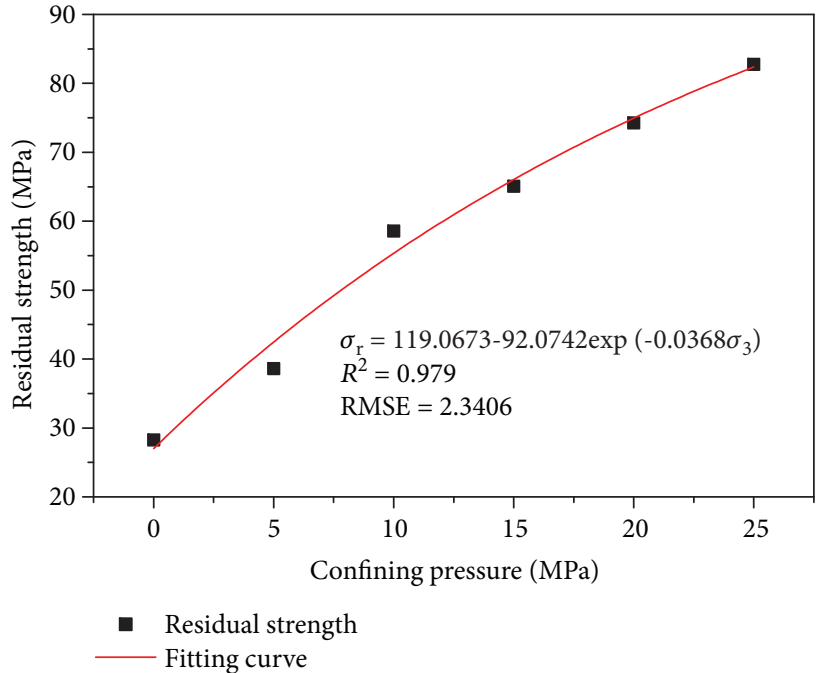

(a)

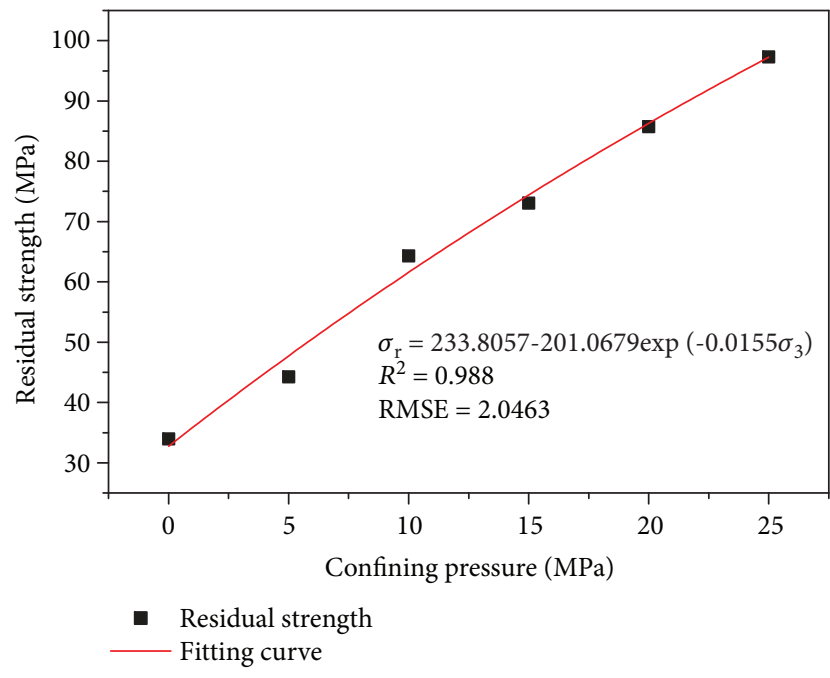

(c)

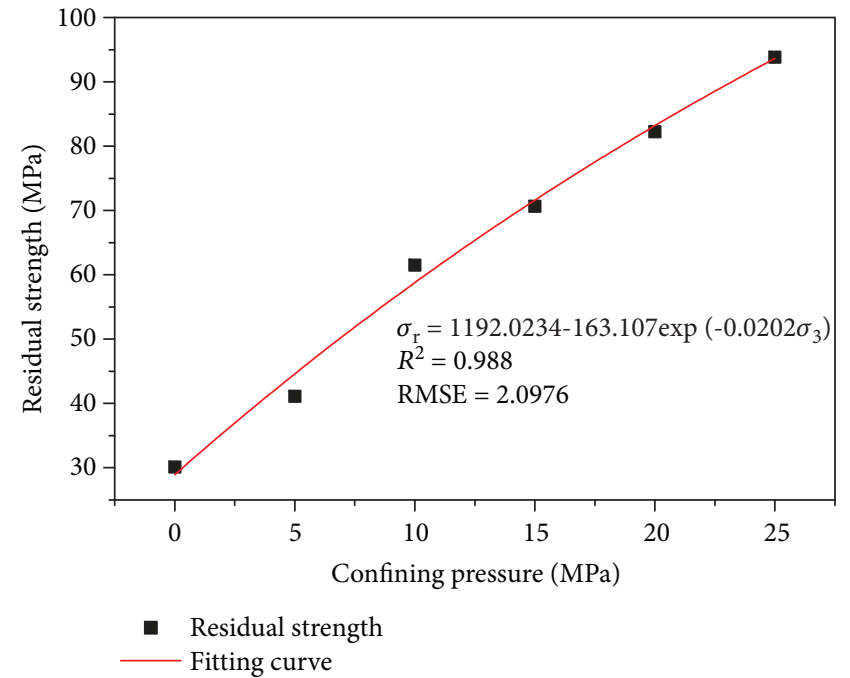

(b)

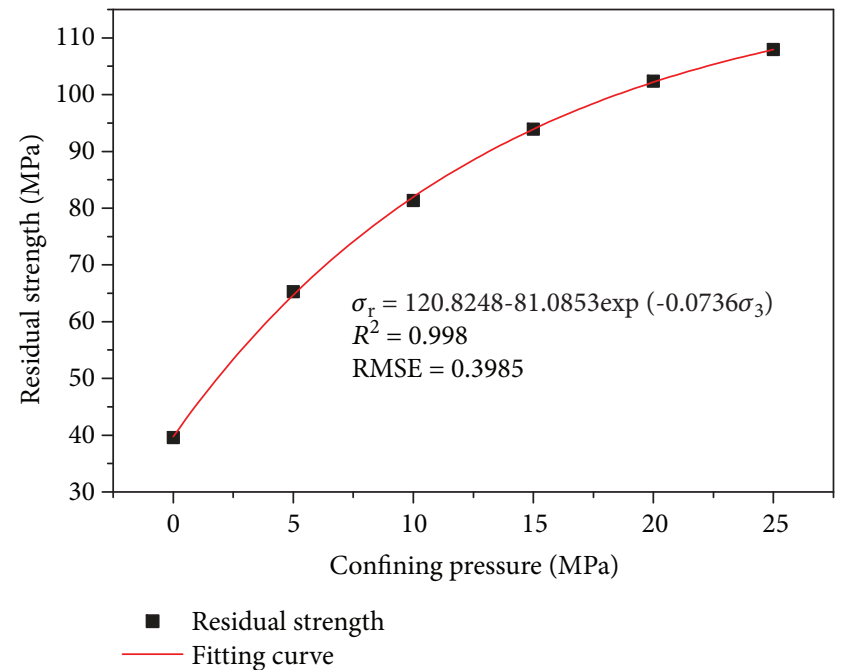

(d)

FIGURE 4: Residual strength at various confining pressures of sandstone specimens treated with different chemical corrosions. The chemical environment is (a) $\mathrm{H}_{2} \mathrm{SO}_{4}$ solution, (b) $\mathrm{NaOH}$ solution, (c) distilled water, and (d) natural state.

TABLE 4: Regression results of residual strength at various confining pressures.

\begin{tabular}{lc}
\hline Chemical environment & Regression equations \\
\hline $\mathrm{H}_{2} \mathrm{SO}_{4}$ solution & $\sigma_{\mathrm{r}}=119.0673-92.0742 \exp \left(-0.0368 \sigma_{3}\right) R^{2}=0.979, \mathrm{RMSE}=2.3406$ \\
$\mathrm{NaOH}$ solution & $\sigma_{\mathrm{r}}=192.0234-163.1076 \exp \left(-0.0202 \sigma_{3}\right) R^{2}=0.988, \mathrm{RMSE}=2.0976$ \\
Distilled water & $\sigma_{\mathrm{r}}=233.8057-201.0679 \exp \left(-0.0155 \sigma_{3}\right) R^{2}=0.988, \mathrm{RMSE}=2.0463$ \\
Natural state & $\sigma_{\mathrm{r}}=120.8248-81.0853 \exp \left(-0.0736 \sigma_{3}\right) R^{2}=0.998, \mathrm{RMSE}=0.3985$ \\
\hline
\end{tabular}

TABle 5: Parameters of sandstone treated with different chemical corrosion (30 MPa).

\begin{tabular}{lccccccccc}
\hline Chemical environment & $\sigma_{\mathrm{p}}(\mathrm{MPa})$ & $\varepsilon_{\mathrm{p}}$ & $E(\mathrm{GPa})$ & $m$ & $F_{0}$ & $\varnothing_{0}(\%)$ & $\varnothing_{t}(\%)$ & $D_{\mathrm{c}}$ & $\lambda$ \\
\hline $\mathrm{H}_{2} \mathrm{SO}_{4}$ solution & 144.14 & 0.0151 & 12.99 & 2.4275 & 188.4859 & 5.08 & 10.76 & 0.0598 & 0.78 \\
Distilled water & 166.47 & 0.0162 & 13.70 & 2.7855 & 222.4475 & 5.14 & 5.94 & 0.0084 & 0.80 \\
NaOH solution & 151.27 & 0.0154 & 13.30 & 2.6737 & 201.4039 & 5.07 & 8.64 & 0.0376 & 0.82 \\
Natural state & 170.86 & 0.0165 & 13.81 & 2.8038 & 230.2525 & 5.11 & 5.11 & 0 & 0.81 \\
\hline
\end{tabular}




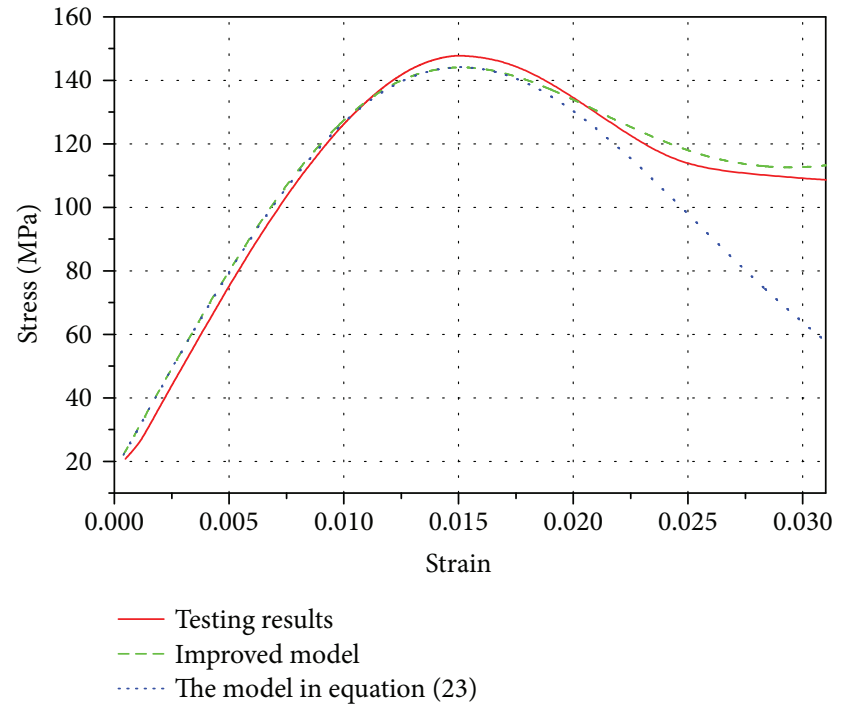

(a)

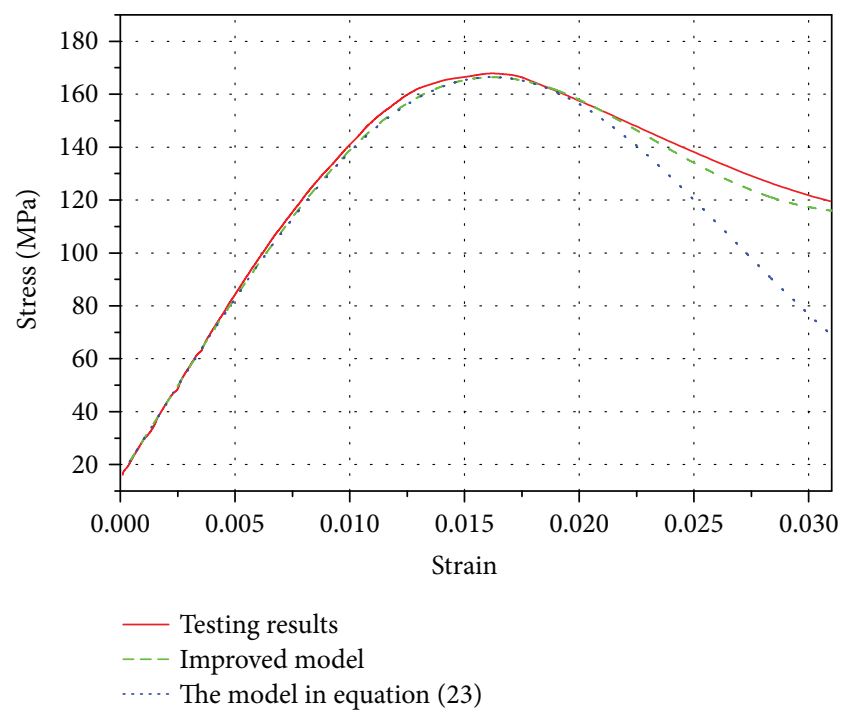

(c)

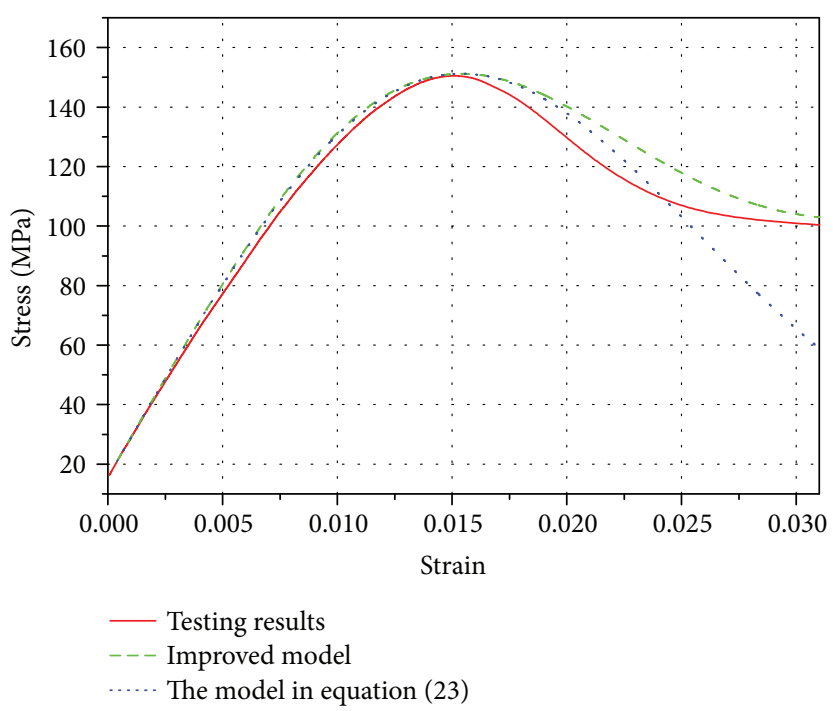

(b)

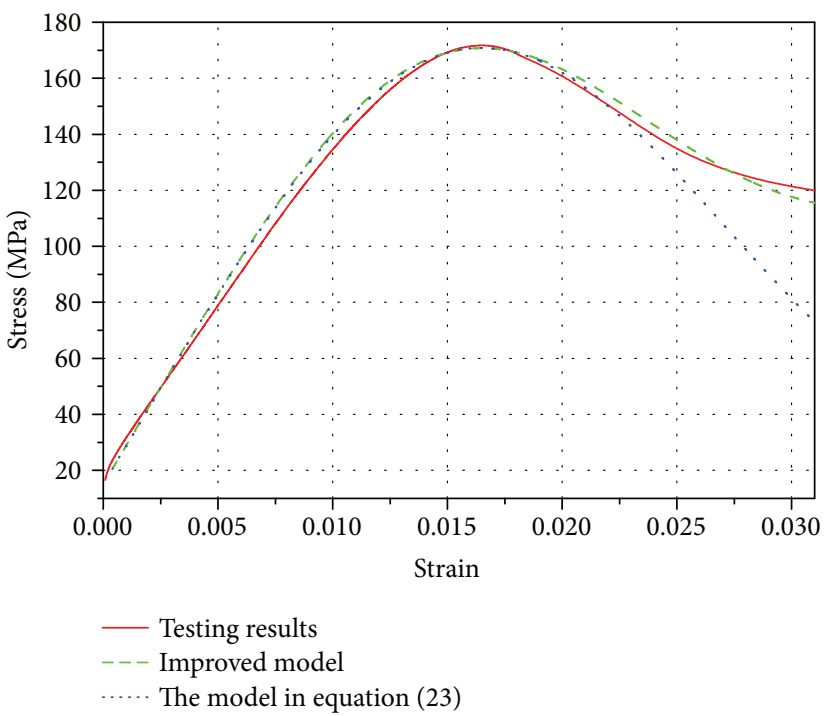

(d)

FIgURE 5: Theoretical curves and test curves of sandstone with different chemical corrosions under a confining pressure of $30 \mathrm{MPa}$ (a) $\mathrm{H}_{2} \mathrm{SO}_{4}$ solutions, (b) $\mathrm{NaOH}$ solution, (c) distilled water, and (d) natural state.

The statistical damage constitutive model established in equation (23) is also simulated to compare the fitting performance of the improved model established in this study. The fitting results of sandstone specimens simulated by the two damage constitutive models and the stress-strain curves of the testing results are shown in Figure 5. Figure 6 shows the coefficient of determination between the two models and experimental data.

From Figure 5, it is obvious that the fitting curves of the improved damage constitutive model proposed in this study are highly similar to the experimental results, and the improved model can well reflect the damage evolution behavior of sandstone treated with chemical corrosion. Compared with the simulation results of the improved model in this study, the fitting results of the model in equation (23) agree well with the testing curves in the pre-peak stage, but the post-peak curves are greatly deviated from the testing curves, which may be caused by the reason that the damage variable correction coefficient is not considered in the model of equation (23).

In Figure 6, the coefficients between the improved model and experimental data are greater 0.98 , indicating that the model is feasible and reliable to describe the mechanical behavior of rocks under a coupled chemical-mechanical condition. Both of the two damage constitutive models have good fitting performance with the coefficients greater than 0.9. It is worth noting that the coefficients of the improved model are larger than that of the model in equation (23), while the values of RMSE of the improved model are smaller, which reveals that the fitting performance of the improved 


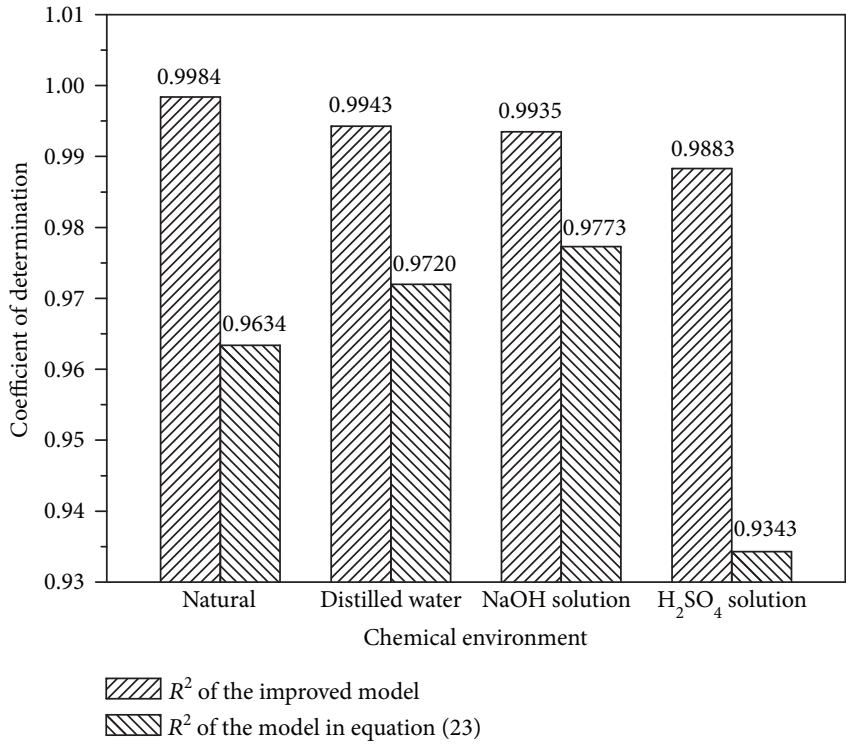

(a)

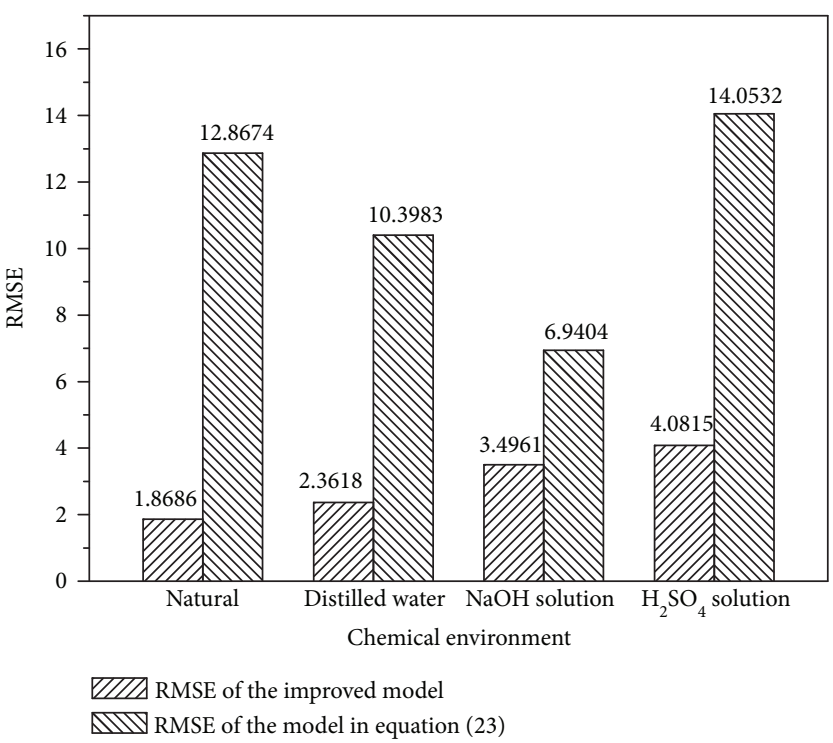

(b)

FIgURE 6: $R^{2}$ and RMSE between the two models and experimental data.

model proposed in this work is better. Figure 6 further reveals that chemical corrosion has influence on the fitting performance of the improved model, and the ascending order of the effect of different chemical corrosions is $\mathrm{H}_{2} \mathrm{SO}_{4}, \mathrm{NaOH}$, and distilled water, respectively. This may be caused by the error between the chemical damage variable calculated in this study and the actual chemical damage of rocks. The former is calculated based on the change of porosity and an approximation of the actual chemical damage variable, and the error increases with the increasing of chemical corrosion. Thus, the effect of $\mathrm{H}_{2} \mathrm{SO}_{4}$ solution and $\mathrm{NaOH}$ solution is larger.

Moreover, the improved curves have an increasing trend in the post-peak stage, which is not in accordance with the testing results. This may be due to that Lemaitre's strainequivalent principle does not take into account that the partial compressive and shear stresses can continue to be propagated after the failure of the microelements of the rock [39]. Therefore, in order to establish a more reasonable statistic constitutive model for rock under the effect of chemical corrosion and loading, more factors should be considered in the future, such as the residual strain and post-peak elastic modulus.

\section{Discussion}

Figure 7 shows the relationships among $m, F_{0}$, and the chemical damage variable of sandstone specimens. The regression results reveal that the relationships can be described by exponential equations shown in equation (30). Figure 7 further shows that $m$ and $F_{0}$ are negatively correlated to the chemical damage variable, and both of them decrease with the chemical damage variable increasing. Based on the results of previous studies [39], $m$ represents the brittleness of rocks and $F_{0}$ is the average macroscopic strength of rocks. As known, both of the brittleness and macroscopic strength of rocks reduce as the chemical damage increases, which is consistent with the evolution law of the two parameters with the chemical damage variable. Thus, the parameter $m$ can reflect the brittleness of sandstone, and $F_{0}$ can be used to describe the rock average strength. Moreover, we can obtain the deterioration characteristics of average strength and brittleness of rocks using the chemical damage variable. It may be a meaningful method to investigate the damage evolution behavior and establish the damage constitutive model of rock based on the relationships between $m, F_{0}$, and chemical damage variable, and this will be the further study.

$$
\left\{\begin{array}{l}
m=-0.0324 \exp \left(\frac{D}{0.0327}\right)+2.8340, R^{2}=0.999 \\
F_{0}=98.6574 \exp \left(-\frac{D}{0.1099}\right)+131.4170, R^{2}=0.999 .
\end{array}\right.
$$

In this study, the method of experimental fitting is used to determine the values of $\sigma_{\mathrm{p}}, \varepsilon_{\mathrm{p}}, E$, and $\sigma_{\mathrm{r}}$. The result showed that the method is convenient and feasible to obtain the Weibull distribution parameters ( $m$ and $F_{0}$ ). Though it is only tested on sandstones under a coupled chemical-mechanical condition, it is expected to be suitable for other types of rocks in various environments. This claim needs verifications in future research.

The two-parameter Weibull distribution is the most widely used distribution function, and the results in this paper and other literatures [27, 42, 53, 54, 57, 58] also indicate that the distribution is capable of describing the strength level of the microelements of rock-like materials, while the three-parameter Weibull distribution is considered to be 


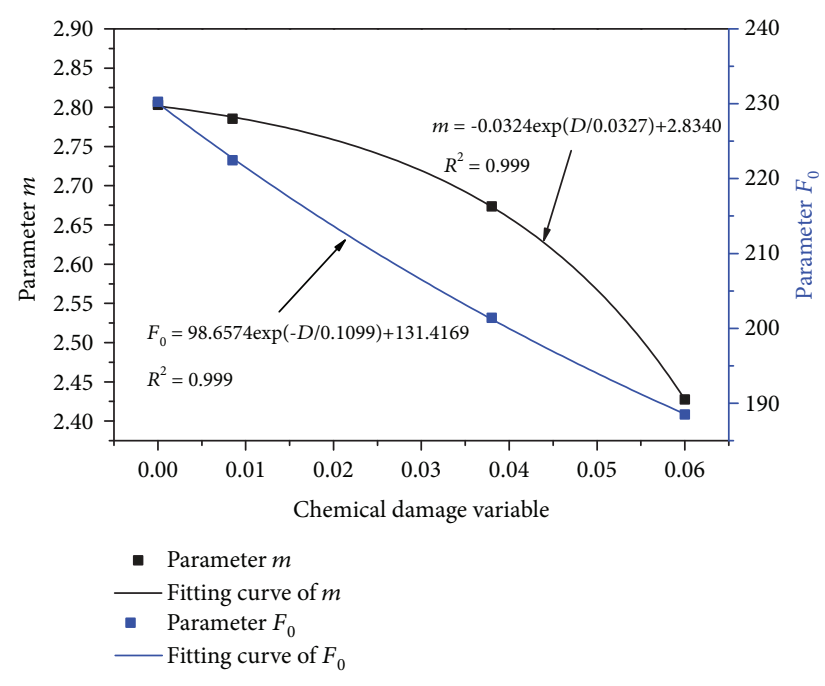

FIgURE 7: The variation of parameters $m$ and $F_{0}$ with different chemical damage variables.

the most valuable statistical distribution and has been applied to establish constitutive models of rocks under a coupled thermal-mechanical condition $[32,86]$. Therefore, it is necessary and meaningful to investigate the constitutive relationship of corroded rocks based on the three-parameter Weibull distribution, which will be carried out in the next work.

Moreover, the aim of this work is to provide an alternative method to describe the damage evolution process of rock under a coupled chemical-mechanical condition. However, it should be noted that it is still far from fully understanding the damage evolution characteristics of rocks. For example, the cumulative damage develops rapidly and the bearing capacity decay rapidly in the post-peak stage of the brittle materials $[39,55]$, then the model in this study would not be suitable.

\section{Conclusions}

In this work, an improved statistical damage constitutive model under a coupled chemical-mechanical condition is established and the following conclusions can be drawn:

(1) An improved statistical damage constitutive model by combining Weibull distribution, chemical damage variable, and correction coefficient is proposed, which considers the chemical effects and residual strength of sandstone in post-peak stage

(2) The chemical damage variable is defined in terms of porosity which can be obtained easily. The elastic modulus of sandstone treated with chemical corrosion can be calculated based on the chemical damage variable and initial elastic modulus of rock in the natural state. The fitting performance of the model would decrease with the chemical damage variable increasing

(3) The relationships between mechanical parameters and confining pressures are determined. The physical meaning of parameters in the damage constitutive model is discussed based on the correlations between the parameters and chemical damage variable, which enhanced the adoptability of the model

(4) Based on testing results, the improved statistical damage constitutive model is verified. The fitting performance of the improved model in this study is better with $R^{2}>0.98$, indicating that the improved model is feasible to describe the damage evolution behavior of sandstone treated with different chemical corrosions. Though the proposed model is only tested on sandstones, the model is expected to be applicable to other types of rocks when the dominant damage mechanism due to chemical corrosion is the same

\section{Symbols}

$\begin{array}{ll}\sigma_{i}: & \text { Nominal stress (MPa) } \\ \sigma_{i}^{*}: & \text { Effective stress (MPa) } \\ D_{\mathrm{m}}: & \text { Material damage variable under load } \\ \lambda: & \text { Damage variable correction coefficient } \\ \sigma_{1}, \sigma_{2}, \sigma_{3}: & \text { Three principal stresses }(\mathrm{MPa}) \\ \varepsilon_{1}: & \text { Strain correspond to the stress of } \sigma_{1} \\ E: & \text { Elastic modulus }(\mathrm{GPa}) \\ \mu: & \text { Poisson's ratio } \\ N_{t}: & \text { Number of failed microelements } \\ N: & \text { Total number of microelements. } \\ P(F): & \text { Microelement strength distribution function } \\ m, F_{0}: & \text { Shape parameter and scale parameter of Weibull } \\ F: & \text { distribution } \\ & \text { Parameter which indicates the strength level of the } \\ D: & \text { microelement } \\ D_{\mathrm{c}}: & \text { Total damage variable } \\ \varnothing_{0}, \varnothing_{t}: & \text { Chemical damage variable } \\ & \text { Initial porosity of specimen, porosity of specimen } \\ & \text { after } t \text { days of immersion in chemical solutions }\end{array}$
(\%)

$E_{0}: \quad \quad \quad \quad \quad \quad$ lastic modulus of rock without chemical corrosion $(\mathrm{GPa})$

$\partial_{0}, k_{0:} \quad$ Material parameters

$I_{1}, J_{2}$ : First invariant of the stress tensor and the second invariant of the stress deviator

$\sigma_{1}^{*}, \sigma_{2}^{*}, \sigma_{3}^{*}$ : Effective stresses of the three principal stresses (MPa)

$\varphi: \quad$ Internal friction angle $\left({ }^{\circ}\right)$

$\sigma_{\mathrm{p}}: \quad$ Peak stress of rock $(\mathrm{MPa})$

$\varepsilon_{\mathrm{p}}$ : $\quad$ Strain corresponding to the peak stress

$F_{\mathrm{p}}$ : $\quad$ Strength of the microelement at peak point

$\sigma_{\mathrm{r}}: \quad$ Residual strength $(\mathrm{MPa})$

c: $\quad$ Cohesion (MPa)

$E_{\text {nat }}: \quad$ Elastic modulus of sandstone specimens under natural state $(\mathrm{GPa})$

RMSE: Root mean square error

$R^{2}$ : Coefficient of determination

$n$ : $\quad$ Number of data points

$\sigma_{i}, \sigma_{i}^{\prime}, \sigma_{a}$ : Actual value, fitting value, and average value of the stress at the $i$ th data point 


\section{Data Availability}

Most of the data generated or analysed during this study are included in this manuscript, and all of the data are available from the corresponding author on reasonable request.

\section{Conflicts of Interest}

The authors declared no potential conflicts of interest with respect to the research, authorship, and/or publication of this article.

\section{Authors' Contributions}

The following are the authors' contributions in this study: Yun Lin-methodology, formal analysis, writing of original draft preparation, and review and editing; Feng Gao-formula derivation and paper revision; Keping Zhou-resources and supervision; Rugao Gao-mechanical testing, review, and editing; and Hongquan Guo-mechanical testing and paper revision.

\section{Acknowledgments}

The research presented in this paper was jointly supported by the National Natural Science Foundation of China (Grant No. 51474252 and No. 51774323), the Project of the State Key Laboratory of Safety and Health for Metal Mines of China (Grant No. 2016-JSKSSYS-02), and the Fundamental Research Funds Project of Central South University (Grant No. 2016zzts095). The first author would like to thank the Chinese Scholarship Council for the financial support to the joint $\mathrm{PhD}$ studies at the University of Adelaide.

\section{References}

[1] Z. Zhou, X. Cai, W. Cao, X. Li, and C. Xiong, "Influence of water content on mechanical properties of rock in both saturation and drying processes," Rock Mechanics and Rock Engineering, vol. 49, no. 8, pp. 3009-3025, 2016.

[2] H. Bai, D. Ma, and Z. Chen, "Mechanical behavior of groundwater seepage in karst collapse pillars," Engineering Geology, vol. 164, pp. 101-106, 2013.

[3] É. Tóth, O. M. N. Dhubhghaill, G. Besson, L. Helm, and A. E. Merbach, "Coordination equilibrium - a clue for fast water exchange on potential magnetic resonance imaging contrast agents?," Magnetic Resonance in Chemistry, vol. 37, no. 10, pp. 701-708, 1999.

[4] T. Han, J. Shi, Y. Chen, Z. Li, and C. Li, "Laboratory investigation on the mechanical properties of sandstone immersed in different chemical corrosion under freeze-thaw cycles," Acta Mechanica Solida Sinica, vol. 38, no. 6, pp. 503-520, 2017.

[5] D. Hu, H. Zhou, Q. Hu, J. Shao, X. Feng, and H. Xiao, “A hydro-mechanical-chemical coupling model for geomaterial with both mechanical and chemical damages considered," Acta Mechanica Solida Sinica, vol. 25, no. 4, pp. 361-376, 2012.

[6] D. W. Hu, H. Zhou, F. Zhang, and J. F. Shao, "Evolution of poroelastic properties and permeability in damaged sandstone," International Journal of Rock Mechanics and Mining Sciences, vol. 47, no. 6, pp. 962-973, 2010.
[7] L. Tang, P. Zhang, and S. Wang, "Testing study on macroscopic mechanics effect of chemical action ojf water on rocks," Chinese Journal of Rock Mechanics and Engineering, vol. 21, pp. 526-531, 2002.

[8] X. Fang, J. Xu, and P. Wang, "Compressive failure characteristics of yellow sandstone subjected to the coupling effects of chemical corrosion and repeated freezing and thawing," Engineering Geology, vol. 233, pp. 160-171, 2018.

[9] X.-T. Feng, S. Chen, and S. Li, "Effects of water chemistry on microcracking and compressive strength of granite," International Journal of Rock Mechanics and Mining Sciences, vol. 38, no. 4, pp. 557-568, 2001.

[10] X.-T. Feng, S. Chen, and H. Zhou, "Real-time computerized tomography (CT) experiments on sandstone damage evolution during triaxial compression with chemical corrosion," International Journal of Rock Mechanics and Mining Sciences, vol. 41, no. 2, pp. 181-192, 2004.

[11] F. Gao, Q. Wang, H. Deng, J. Zhang, W. Tian, and B. Ke, "Coupled effects of chemical environments and freeze-thaw cycles on damage characteristics of red sandstone," Bulletin of Engineering Geology and the Environment, vol. 76, no. 4, pp. 1481-1490, 2017.

[12] T. Han, J. Shi, and X. Cao, "Fracturing and damage to sandstone under coupling effects of chemical corrosion and freeze-thaw cycles," Rock Mechanics and Rock Engineering, vol. 49, no. 11, pp. 4245-4255, 2016.

[13] T. Han, J. Shi, Y. Chen, and X. Cao, "Physical and mechanical properties of marble under the combined effects of chemical solutions and freeze-thaw cycles," Geotechnical Testing Journal, vol. 40, no. 6, article 20160225, 2017.

[14] M. Kaczmarek and T. Hueckel, "Chemo-mechanical consolidation of clays: analytical solutions for a linearized onedimensional problem," Transport in Porous Media, vol. 32, no. 1, pp. 49-74, 1998.

[15] H. Li, D. Yang, Z. Zhong, Y. Sheng, and X. Liu, "Experimental investigation on the micro damage evolution of chemical corroded limestone subjected to cyclic loads," International Journal of Fatigue, vol. 113, pp. 23-32, 2018.

[16] L. Ning, Z. Yunming, S. Bo, and S. Gunter, "A chemical damage model of sandstone in acid solution," International Journal of Rock Mechanics and Mining Sciences, vol. 40, no. 2, pp. 243249, 2003.

[17] S. Miao, M. Cai, Q. Guo, P. Wang, and M. Liang, "Damage effects and mechanisms in granite treated with acidic chemical solutions," International Journal of Rock Mechanics and Mining Sciences, vol. 88, pp. 77-86, 2016.

[18] L. Qiao, Z. Wang, and A. Huang, "Alteration of mesoscopic properties and mechanical behavior of sandstone due to hydro-physical and hydro-chemical effects," Rock Mechanics and Rock Engineering, vol. 50, no. 2, pp. 255-267, 2017.

[19] W. Ding and X. Feng, “Testing study on mechanical effect for limestone under chemical erosion," Chinese Journal of Rock Mechanics and Engineering, vol. 23, pp. 3571-3576, 2004.

[20] L. J. Feucht and J. M. Logan, "Effects of chemically active solutions on shearing behavior of a sandstone," Tectonophysics, vol. 175, no. 1-3, pp. 159-176, 1990.

[21] J. H. Dieterich and G. Conrad, "Effect of humidity on timeand velocity-dependent friction in rocks," Journal of Geophysical Research: Solid Earth, vol. 89, no. B6, pp. 4196-4202, 1984.

[22] J. Logan and M. Blackwell, "The influence of chemically active fluids on the frictional behavior of sandstone," EOS 
Transactions of the American Geophysical Union, vol. 64, pp. 835-837, 1983.

[23] J. Ni, Y.-L. Chen, P. Wang, S.-R. Wang, B. Peng, and R. Azzam, "Effect of chemical erosion and freeze-thaw cycling on the physical and mechanical characteristics of granites," Bulletin of Engineering Geology and the Environment, vol. 76, no. 1, pp. 169-179, 2017.

[24] A. Chowdhury, "Constitutive modelling and Weibull statistical analysis for the porosity-mechanical property correlations in 3\% yittria-stabilized zirconia system," International Journal of Refractory Metals and Hard Materials, vol. 70, pp. 246-252, 2018.

[25] K. Khaledi, E. Mahmoudi, M. Datcheva, D. König, and T. Schanz, "Sensitivity analysis and parameter identification of a time dependent constitutive model for rock salt," Journal of Computational and Applied Mathematics, vol. 293, pp. 128-138, 2016.

[26] X. S. Liu, J. G. Ning, Y. L. Tan, and Q. H. Gu, "Damage constitutive model based on energy dissipation for intact rock subjected to cyclic loading," International Journal of Rock Mechanics and Mining Sciences, vol. 85, pp. 27-32, 2016.

[27] S. Chen, C. Qiao, Q. Ye, and M. U. Khan, "Comparative study on three-dimensional statistical damage constitutive modified model of rock based on power function and Weibull distribution," Environmental Earth Sciences, vol. 77, no. 3, 2018.

[28] S. Huang, Q. Liu, A. Cheng, and Y. Liu, "A statistical damage constitutive model under freeze-thaw and loading for rock and its engineering application," Cold Regions Science and Technology, vol. 145, pp. 142-150, 2018.

[29] G. Li and C.-A. Tang, "A statistical meso-damage mechanical method for modeling trans-scale progressive failure process of rock," International Journal of Rock Mechanics and Mining Sciences, vol. 74, pp. 133-150, 2015.

[30] J. Deng and D. Gu, "On a statistical damage constitutive model for rock materials," Computers \& Geosciences, vol. 37, no. 2, pp. 122-128, 2011.

[31] C. Gao, L. Z. Xie, H. P. Xie et al., "Coupling between the statistical damage model and permeability variation in reservoir sandstone: theoretical analysis and verification," Journal of Natural Gas Science and Engineering, vol. 37, pp. 375-385, 2017.

[32] M. Gao, T. Li, T. Wei, and L. Meng, "A statistical constitutive model considering deterioration for brittle rocks under a coupled thermal-mechanical condition," Geofluids, vol. 2018, 10 pages, 2018.

[33] Z. Wang, Y. Li, and J. G. Wang, "A damage-softening statistical constitutive model considering rock residual strength," Computers \& Geosciences, vol. 33, no. 1, pp. 1-9, 2007.

[34] H. Fu, J. Zhang, Z. Huang, Y. Shi, and W. Chen, “A statistical model for predicting the triaxial compressive strength of transversely isotropic rocks subjected to freeze-thaw cycling," Cold Regions Science and Technology, vol. 145, pp. 237-248, 2018.

[35] S. Li, Y. Lai, S. Zhang, and D. Liu, "An improved statistical damage constitutive model for warm frozen clay based on Mohr-Coulomb criterion," Cold Regions Science and Technology, vol. 57, no. 2-3, pp. 154-159, 2009.

[36] X. Li, W.-G. Cao, and Y.-H. Su, "A statistical damage constitutive model for softening behavior of rocks," Engineering Geology, vol. 143-144, pp. 1-17, 2012.

[37] H. Zhao, C. Zhang, W. Cao, and M. Zhao, "Statistical mesodamage model for quasi-brittle rocks to account for damage tolerance principle," Environmental Earth Sciences, vol. 75, no. 10, 2016.

[38] M. Ismael and H. Konietzky, "Constitutive model for inherent anisotropic rocks: ubiquitous joint model based on the Hoek-Brown failure criterion," Computers and Geotechnics, vol. 105, pp. 99-109, 2019.

[39] X. Xu, F. Gao, and Z. Zhang, “Thermo-mechanical coupling damage constitutive model of rock based on the Hoek-Brown strength criterion," International Journal of Damage Mechanics, vol. 27, no. 8, pp. 1213-1230, 2017.

[40] O. Pourhosseini and M. Shabanimashcool, "Development of an elasto-plastic constitutive model for intact rocks," International Journal of Rock Mechanics and Mining Sciences, vol. 66, pp. 1-12, 2014.

[41] L. Jiang and Y. Wen, "Damage constitutive model of sandstone during corrosion by AMD," Journal of Central South University (Science and Technology), vol. 42, no. 11, pp. 3502-3506, 2011.

[42] S. Miao, H. Wang, M. Cai, Y. Song, and J. Ma, "Damage constitutive model and variables of cracked rock in a hydrochemical environment," Arabian Journal of Geosciences, vol. 11, no. 2, p. 19, 2018.

[43] D. Fereidooni, G. R. Khanlari, M. Heidari, A. A. Sepahigero, and A. P. Kolahi-Azar, "Assessment of inherent anisotropy and confining pressure influences on mechanical behavior of anisotropic foliated rocks under triaxial compression," Rock Mechanics and Rock Engineering, vol. 49, no. 6, pp. 21552163, 2016.

[44] M. Hokka, J. Black, D. Tkalich et al., "Effects of strain rate and confining pressure on the compressive behavior of kuru granite," International Journal of Impact Engineering, vol. 91, pp. 183-193, 2016.

[45] S. Yu, H. Deng, and Y. Zhang, "The constitutive relationship of rock damage considering the effect of temperature and confining pressure," Journal of Railway Science and Engineering, vol. 15, pp. 1-9, 2018.

[46] J. Lemaitre, "A continuous damage mechanics model for ductile fracture," Journal of Engineering Materials and Technology, vol. 107, no. 1, pp. 83-89, 1985.

[47] B. Wang, F. Wang, and Q. Wang, "Damage constitutive models of concrete under the coupling action of freeze-thaw cycles and load based on Lemaitre assumption," Construction and Building Materials, vol. 173, pp. 332-341, 2018.

[48] J. Qian and Z. Yin, Geotechnical Principles and Calculation, China Water Resource and Hydropower Press, Beijing, China, 1994.

[49] K. Dovstam, "Augmented Hooke's Law in frequency domain. A three dimensional, material damping formulation," International Journal of Solids and Structures, vol. 32, no. 19, pp. 2835-2852, 1995.

[50] B. T. Brady, "A statistical theory of brittle fracture for rock materials part I-brittle failure under homogeneous axisymmetric states of stress," International Journal of Rock Mechanics and Mining Sciences \& Geomechanics Abstracts, vol. 6, no. 1, pp. 21-42, 1969.

[51] W. Weibull, "A statistical distribution function of wide applicability,” Journal of Applied Mechanics, vol. 18, pp. 293-297, 1951.

[52] D. Krajcinovic and M. A. G. Silva, "Statistical aspects of the continuous damage theory," International Journal of Solids and Structures, vol. 18, no. 7, pp. 551-562, 1982. 
[53] M. R. M. Aliha and M. R. Ayatollahi, "Rock fracture toughness study using cracked chevron notched Brazilian disc specimen under pure modes I and II loading - a statistical approach," Theoretical and Applied Fracture Mechanics, vol. 69, pp. 17-25, 2014.

[54] N. Erarslan, Z. Z. Liang, and D. J. Williams, "Experimental and numerical studies on determination of indirect tensile strength of rocks," Rock Mechanics and Rock Engineering, vol. 45, pp. 739-751, 2012.

[55] X. Xu, M. Karakus, F. Gao, and Z. Zhang, "Thermal damage constitutive model for rock considering damage threshold and residual strength," Journal of Central South University, vol. 25, no. 10, pp. 2523-2536, 2018.

[56] B. Deng, D. Jiang, and J. Gong, "Is a three-parameter Weibull function really necessary for the characterization of the statistical variation of the strength of brittle ceramics?," Journal of the European Ceramic Society, vol. 38, no. 4, pp. 2234-2242, 2018.

[57] T. Saksala, "Damage-viscoplastic consistency model with a parabolic cap for rocks with brittle and ductile behavior under low-velocity impact loading," International Journal for Numerical and Analytical Methods in Geomechanics, vol. 34, no. 13, pp. 1362-1386, 2010.

[58] M. Sari and C. Karpuz, "Rock variability and establishing confining pressure levels for triaxial tests on rocks," International Journal of Rock Mechanics and Mining Sciences, vol. 43, no. 2, pp. 328-335, 2006.

[59] B. Ke, K. Zhou, C. Xu, H. Deng, J. Li, and F. Bin, "Dynamic mechanical property deterioration model of sandstone caused by freeze-thaw weathering," Rock Mechanics and Rock Engineering, vol. 51, no. 9, pp. 2791-2804, 2018.

[60] R. Peng, Y. Yang, Y. Ju, L. Mao, and Y. Yang, "Computation of fractal dimension of rock pores based on gray CT images," Chinese Science Bulletin, vol. 56, no. 31, 2011.

[61] J. Teng, J. Tang, Y. Zhang, and X. Li, "CT experimental study on the damage characteristics of anchored layered rocks," KSCE Journal of Civil Engineering, vol. 22, no. 9, pp. 36533662, 2018.

[62] Y. Wang, X. Li, B. Zhang, and Y. Wu, "Meso-damage cracking characteristics analysis for rock and soil aggregate with CT test," Science China Technological Sciences, vol. 57, no. 7, pp. 1361-1371, 2014.

[63] H. Chen, H. Tang, and S. Ye, "Damage model of control fissure in perilous rock," Applied Mathematics and Mechanics, vol. 27, no. 7, pp. 967-974, 2006.

[64] J. Jin, X. Li, Z. Yin, and Y. Zou, "A method for defining rock damage variable by wave impedance under cyclic impact loadings," Rock and Soil Mechanics, vol. 32, pp. 1385-1393, 2011.

[65] J.-Q. Xiao, D.-X. Ding, F.-L. Jiang, and G. Xu, "Fatigue damage variable and evolution of rock subjected to cyclic loading," International Journal of Rock Mechanics and Mining Sciences, vol. 47, no. 3, pp. 461-468, 2010.

[66] G. Lu, E. Yan, X. Wang, L. Xie, and L. Gao, "Study of impact of fractal dimension of pore distribution on compressive strength of porous material," Rock and Soil Mechanics, vol. 35, pp. 2261-2269, 2014.

[67] L. M. Kachanov, "Rupture time under creep conditions," International Journal of Fracture, vol. 97, no. 1/4, pp. 11-18, 1999.

[68] G. Li, C.-A. Tang, and Z.-Z. Liang, "Development of a parallel FE simulator for modeling the whole trans-scale failure process of rock from meso- to engineering-scale," Computers \& Geosciences, vol. 98, pp. 73-86, 2017.

[69] L. C. Li, C. A. Tang, S. Y. Wang, and J. Yu, "A coupled thermohydrologic-mechanical damage model and associated application in a stability analysis on a rock pillar," Tunnelling and Underground Space Technology, vol. 34, pp. 38-53, 2013.

[70] D. C. Drucker and W. Prager, "Soil mechanics and plastic analysis or limit design," Quarterly of Applied Mathematics, vol. 10, no. 2, pp. 157-165, 1952.

[71] R. I. Borja, R. A. Regueiro, and T. Y. Lai, "FE modeling of strain localization in soft rock," Journal of Geotechnical and Geoenvironmental Engineering, vol. 126, no. 4, pp. 335-343, 2000.

[72] B. Loret and J. H. Prevost, "Accurate numerical solutions for Drucker-Prager elastic-plastic models," Computer Methods in Applied Mechanics and Engineering, vol. 54, no. 3, pp. 259-277, 1986.

[73] V. Mazel, H. Diarra, V. Busignies, and P. Tchoreloff, "Comparison of different failure tests for pharmaceutical tablets: applicability of the Drucker-Prager failure criterion," International Journal of Pharmaceutics, vol. 470, no. 1-2, pp. 63-69, 2014.

[74] Z. T. Bieniawski and M. J. Bernede, "Suggested methods for determining the uniaxial compressive strength and deformability of rock materials," International Journal of Rock Mechanics and Mining Sciences \& Geomechanics Abstracts, vol. 16, no. 2, pp. 138-140, 1979.

[75] Z. Zhou, X. Cai, L. Chen, W. Cao, Y. Zhao, and C. Xiong, "Influence of cyclic wetting and drying on physical and dynamic compressive properties of sandstone," Engineering Geology, vol. 220, pp. 1-12, 2017.

[76] W. Rühaak, C.-D. Heldmann, L. Pei, and I. Sass, "Thermohydro-mechanical-chemical coupled modeling of a geothermally used fractured limestone," International Journal of Rock Mechanics and Mining Sciences, vol. 100, pp. 40-47, 2017.

[77] A. R. Adebayo, M. E. Kandil, T. M. Okasha, and M. L. Sanni, "Measurements of electrical resistivity, NMR pore size and distribution, and x-ray CT-scan for performance evaluation of $\mathrm{CO}_{2}$ injection in carbonate rocks: a pilot study," International Journal of Greenhouse Gas Control, vol. 63, pp. 1-11, 2017.

[78] A. Z. Al-Yaseri, M. Lebedev, S. J. Vogt, M. L. Johns, A. Barifcani, and S. Iglauer, "Pore-scale analysis of formation damage in Bentheimer sandstone with in-situ NMR and micro-computed tomography experiments," Journal of Petroleum Science and Engineering, vol. 129, pp. 48-57, 2015.

[79] J. Li, K. Zhou, W. Liu, and H. Deng, "NMR research on deterioration characteristics of microscopic structure of sandstones in freeze-thaw cycles," Transactions of Nonferrous Metals Society of China, vol. 26, no. 11, pp. 2997-3003, 2016.

[80] C. Liu, H. Deng, Y. Wang, Y. Lin, and H. Zhao, "Time-varying characteristics of granite microstructures after cyclic dynamic disturbance using nuclear magnetic resonance," Crystals, vol. 7, no. 10, pp. 306-317, 2017.

[81] H. Liu, L. Xiao, F. Deng, W. Chen, and P. Galvosas, "Emerging NMR approaches for characterizing rock heterogeneity," Microporous and Mesoporous Materials, vol. 269, pp. 118121,2018

[82] X. Yang, L. Weng, and Z. Hu, "Damage evolution of rocks under triaxial compressions: an NMR investigation," KSCE Journal of Civil Engineering, vol. 22, no. 8, pp. 2856-2863, 2018.

[83] Y. Zhao, G. Zhu, Y. Dong, N. N. Danesh, Z. Chen, and T. Zhang, "Comparison of low-field NMR and microfocus 
X-ray computed tomography in fractal characterization of pores in artificial cores," Fuel, vol. 210, pp. 217-226, 2017.

[84] K.-p. Zhou, B. Li, J. L. Li, H. W. Deng, and F. Bin, "Microscopic damage and dynamic mechanical properties of rock under freeze-thaw environment," Transactions of Nonferrous Metals Society of China, vol. 25, no. 4, pp. 1254-1261, 2015.

[85] S.-Q. Yang, P. Xu, and P. G. Ranjith, "Damage model of coal under creep and triaxial compression," International Journal of Rock Mechanics and Mining Sciences, vol. 80, pp. 337-345, 2015.

[86] X. L. Xu and M. Karakus, "A coupled thermo-mechanical damage model for granite," International Journal of Rock Mechanics and Mining Sciences, vol. 103, pp. 195-204, 2018.

[87] H. Jiang, "Simple three-dimensional Mohr-Coulomb criteria for intact rocks," International Journal of Rock Mechanics and Mining Sciences, vol. 105, pp. 145-159, 2018.

[88] J. Shen, S. D. Priest, and M. Karakus, "Determination of Mohr-Coulomb shear strength parameters from generalized Hoek-Brown criterion for slope stability analysis," Rock Mechanics and Rock Engineering, vol. 45, no. 1, pp. 123-129, 2012.

[89] M. Singh, A. Raj, and B. Singh, "Modified Mohr-Coulomb criterion for non-linear triaxial and polyaxial strength of intact rocks," International Journal of Rock Mechanics and Mining Sciences, vol. 48, no. 4, pp. 546-555, 2011.

[90] A. I. Sofianos and P. P. Nomikos, "Equivalent Mohr-Coulomb and generalized Hoek-Brown strength parameters for supported axisymmetric tunnels in plastic or brittle rock," International Journal of Rock Mechanics and Mining Sciences, vol. 43, no. 5, pp. 683-704, 2006.

[91] N. N. Sirdesai, A. Singh, L. K. Sharma, R. Singh, and T. N. Singh, "Determination of thermal damage in rock specimen using intelligent techniques," Engineering Geology, vol. 239, pp. 179-194, 2018. 

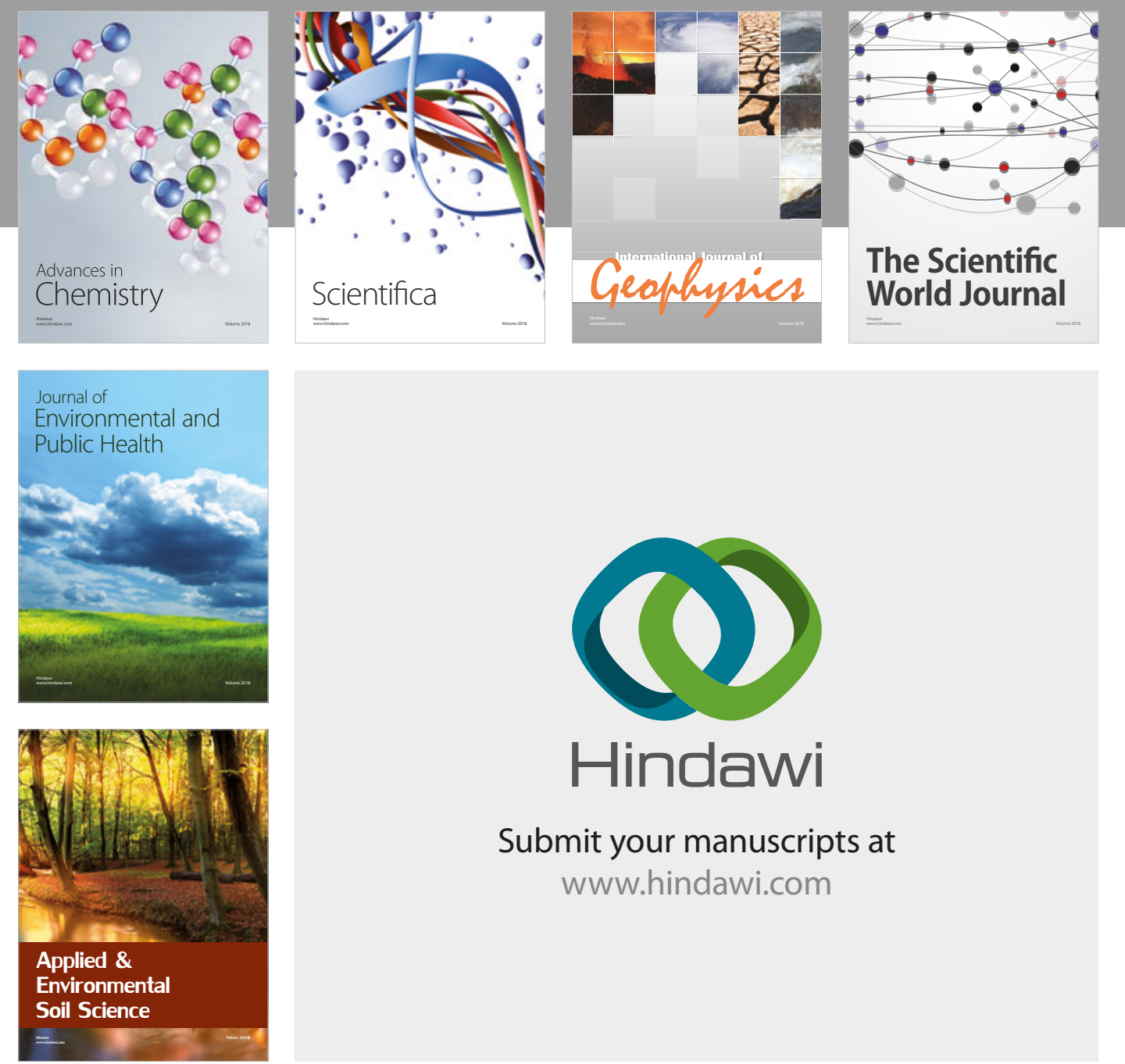

The Scientific

\section{World Journal}
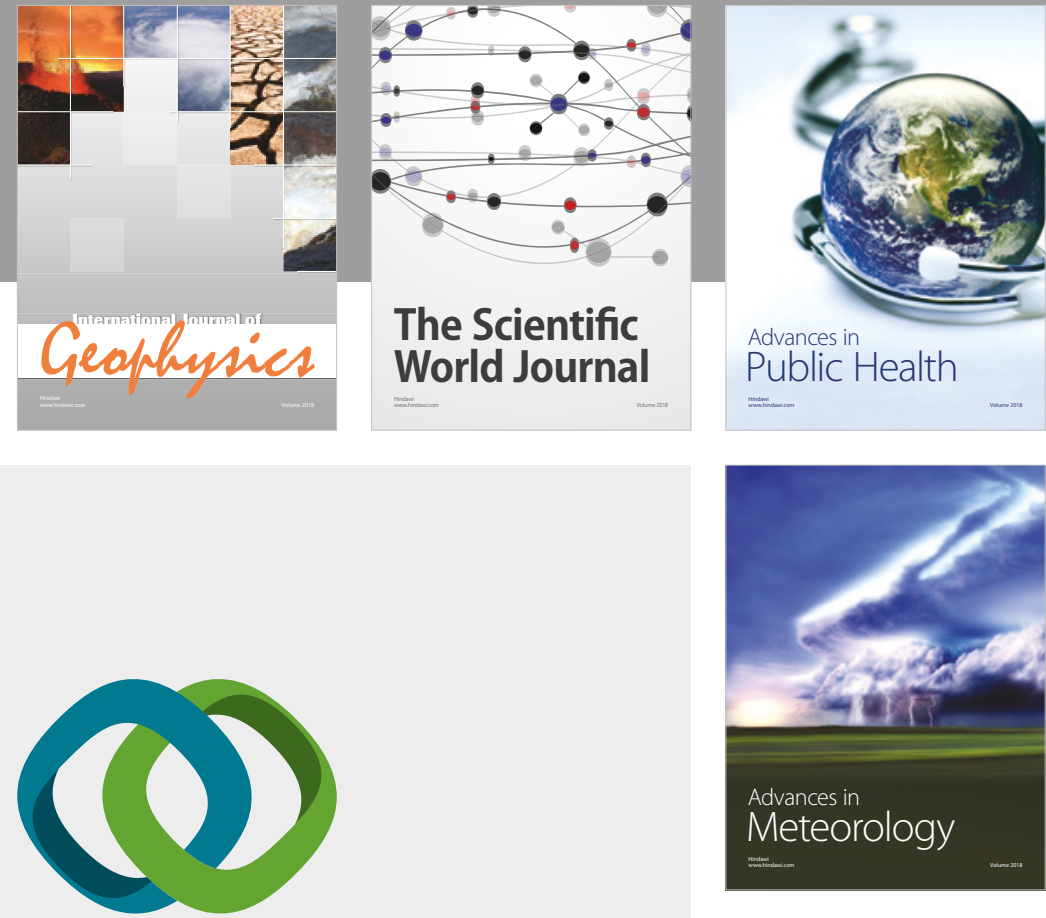

Advan

Public Health

\section{Hindawi}

Submit your manuscripts at

www.hindawi.com
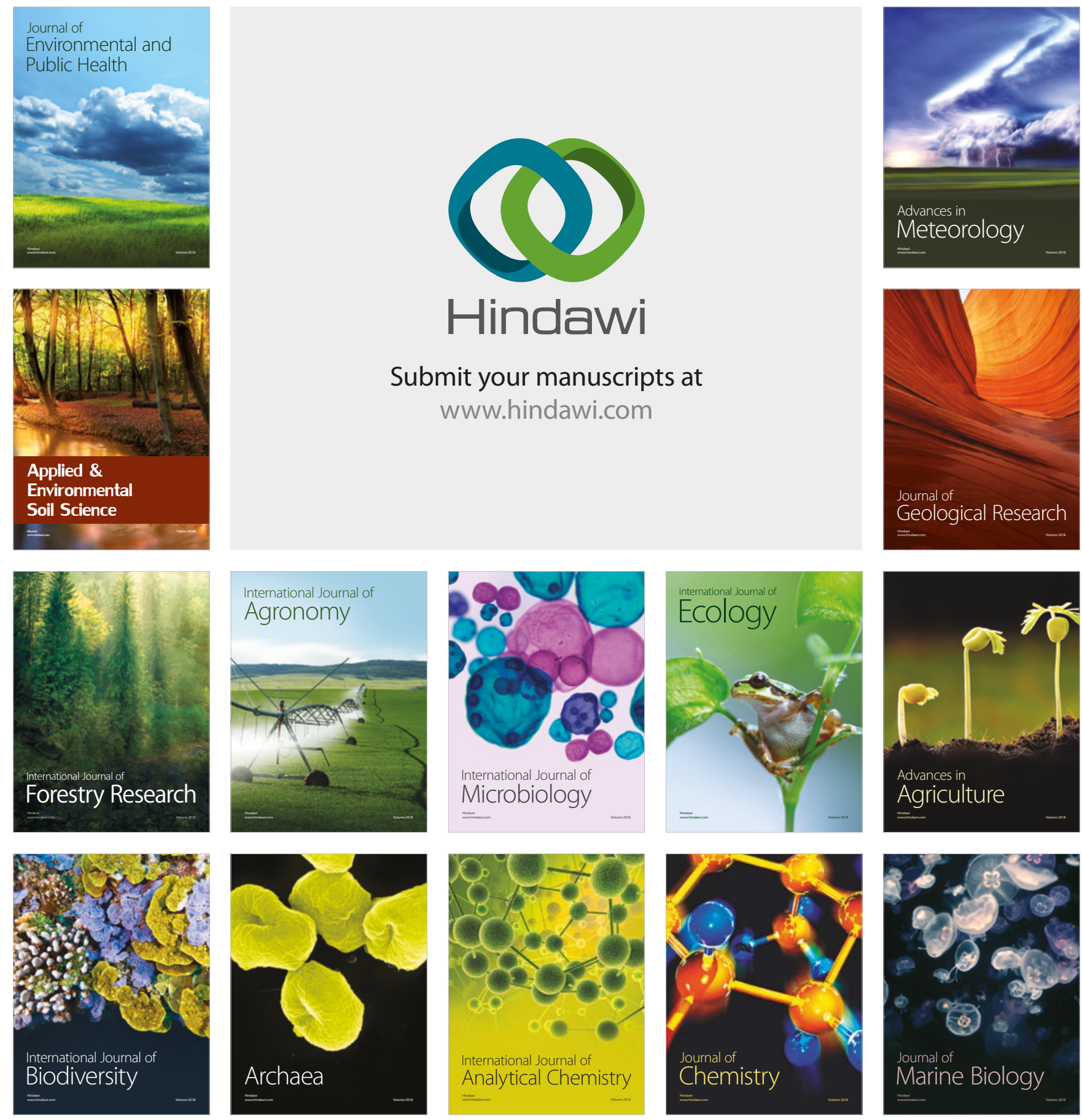